\title{
Performance of Oxalic Acid-Chitosan/Alumina Ceramic Biocomposite for the Adsorption of a Reactive Anionic Azo Dye
}

\section{John Pérez-Calderón}

CIDCA: Centro de Investigacion y Desarrollo en Criotecnologia de Alimentos

\section{Alberto Scian}

CETMIC: Centro de Tecnologia de Recursos Minerales y Ceramica

Martin Ducos

IPATEC-CONICET

\section{Victoria Santos}

IPATEC-CONICET

Noemi Elisabet Zaritzky ( $\nabla$ zaritzkynoemi@gmail.com )

Universida Nacional de La Plata Facultad de Ingenieria lata https://orcid.org/0000-0002-6814-1112

\section{Research Article}

Keywords: Biocomposite, Cross-linked Chitosan, Dye adsorption, Alumina Ceramic

Posted Date: March 9th, 2021

DOl: https://doi.org/10.21203/rs.3.rs-232589/v1

License: (c) (i) This work is licensed under a Creative Commons Attribution 4.0 International License. Read Full License

Version of Record: A version of this preprint was published at Environmental Science and Pollution Research on July 9th, 2021. See the published version at https://doi.org/10.1007/s11356-021-15123-7. 


\title{
Performance of Oxalic Acid-Chitosan/Alumina Ceramic Biocomposite for the Adsorption of a Reactive Anionic Azo Dye
}

\author{
John Pérez-Calderón ${ }^{\text {; }}$ Alberto Scian ${ }^{2}$; MartinDucos ${ }^{3}$; Victoria Santos ${ }^{3}$; Noemí Zaritzky *1,4 \\ ${ }^{1}$ CIDCA (Centro de Investigación y Desarrollo en Criotecnología de Alimentos) CONICET-Facultad de \\ Ciencias Exactas UNLP, CIC-PBA, Calle 47 y 116. La Plata- Buenos Aires .Argentina \\ ${ }^{2}$ CETMIC (Centro de Tecnología de Recursos Minerales y Cerámica) CONICET- CIC-PBA, Gonnet-La Plata \\ 3IPATEC (Instituto Andino Patagónico de Tecnologías Biológicas y Geoambientales) CONICET .Quintral \\ 1250, Bariloche, Argentina \\ ${ }^{4}$ Depto. de Ingeniería Química- Facultad de Ingeniería (Univ. Nacional de La Plata, Argentina), Calle 1 y 47 \\ La Plata
}

${ }^{*}$ Corresponding author: Address: CIDCA- Fac. Cs. Exactas UNLP- Calle 47 y 116-La Plata (1900) ARGENTINA Tel-FAX 54-221-4254853/4249287/4890741.

zaritzkynoemi@gmail.com

\section{Abstract}

A biocomposite system was developed and tested for the removal of the azo dye Reative Red (RR195) from wastewater. The biocomposite was synthesized using ceramic particles containing $75 \%$ alumina which were coated using chitosan crosslinked with oxalic acid. The biocomposite showed high performance at low $\mathrm{pH}$ (maximum adsorption capacity $=345.3 \mathrm{mg} \cdot \mathrm{g}^{-1}$ at $\mathrm{pH}=2$ ). The physico-chemical and structure characteristics of the matrix were evaluated by Z-potential, FTIRATR, SEM-EDS, DRX and porosity. Langmuir sorption isotherm and Pseudo Second order model gave the best fit. The electrostatic interaction between RR195 (due to the sulfonate groups) and the free amino groups of chitosan, enabled successive desorption/regeneration cycles. The maximum removal percentage ( $>80 \%$ ) occurred at $\mathrm{pH}=2$ due to the crosslinking effect. Experiments at different temperatures allowed the calculation of thermodynamic parameters $(\Delta \mathrm{G}, \Delta \mathrm{S}, \Delta \mathrm{H})$; adsorption was spontaneous, exothermic and enthalpy controlled. The presence of inorganic ions $\left(\mathrm{NO}_{3}^{-}>\mathrm{Cl}^{-}\right)$was analyzed during the adsorption process. This novel biocomposite can be applied as a cost-effective and environmentally friendly adsorbent for anionic azo dye removal from wastewater. The application of chitosan crosslinked with oxalic acid as a coating of the ceramic support enhanced the adsorption capacity and enabled its use under acidic conditions without solubilization.

\section{Key words}

Biocomposite; Cross-linked Chitosan; Dye adsorption; Alumina Ceramic

\section{Introduction}

The global production of dyes reaches nearly 800,000 tons per year (Manzoor and Sharma 2020). According to estimates, in the textile industry around 100 tons of dyes are discharged due to the coloring of fibers, which generates a great environmental problem (Yagub et al. 2014). The wastewater containing these pollutants directly affects the photosynthetic capacity of aquatic plant 
species. Additionally the chemical structure of the dyes contributes to a high level of organic matter content negatively affecting the water quality (Crini 2006).

More than 10,000 dyes are used in the textile industry, from these $70 \%$ are azo dyes (Hassaan and Nemr 2017). The presence of azo-reactive dyes cause human health problems being responsible for mutagenesis and leading to several pathologies such as carcinogenesis, respiratory deficiency and jaundice (Alver and Metin, 2012; Vakili et al., 2014) . Structurally, azo dyes are ionic molecules consisting of a chromophore (azo group, $-\mathrm{N}=\mathrm{N}-$ ) and sulfonate groups $\left(-\mathrm{SO}_{3}^{-}\right)$ (Hunger, 2003, Hassaan and Nemr, 2017).

Adsorption is applied for dye removal of wastewater (Crini and Badot 2008); it is highly used due to the facility of full-scale operation, in addition, different inexpensive materials with low toxicity levels can be used as adsorbents (Crini et al. 2019). The introduction of efficient sorbents as biocomposite materials is an alternative to conventional adsorbents. Biocomposite sorbents are heterogeneous systems containing two or more constituents that produce a synergistic effect by improving their adsorption capacity, therefore these materials are used in the water purification technologies (Srinivasan and Viraraghavan, 2010). In order to formulate biocomposite sorbents, two types of materials are necessary: an inorganic support and a biodegradable active component. A widely used biopolymer is chitosan (Ch) because it has proven to be an effective adsorbent (Crini 2015) .

Ch is a nitrogenous (amino-based) polysaccharide (poly- $\beta$-( $1 \rightarrow 4)$-2-amino-2-deoxy-D-glucose); this biopolymer is non-toxic obtained from chitin, formed by de-acetylated units ( $\beta$-(1-4)-Dglucosamine) and acetylated units (N-acetyl-D-glucosamine). Ch is characterized for its a natural poly-cationic, this is due to the existence of structurally de-acetylated units that generate free amino groups $\left(\mathrm{NH}_{3}^{+}\right)$(in acidic conditions); this property allows chitosan to be used for the treatment of wastewater (Crini and Badot 2008). The protonated amino groups of Ch allow the adsorption of dyes by an electrostatic attraction mechanism (Crini and Badot 2008). Pérez-Calderón et al.,(2018) reported the use of chitosan coacervated hydrogels $(\mathrm{CP})$ for the adsorption of the azo dye Reactive Red 195 (RR195) demonstrating that this material has an excellent removal performance.

Wastewater contaminated with dyes is often acidic enabling the solubilization of chitosan due to the protonation of the amine groups, therefore biopolymer modification using cross-linking agents can usually circumvent the problem of instability at low pH (Crini et al. 2019). Covalent cross-linking agents have been used, in particular glutaraldehyde and epichlorhydrin (Crini et al. 2019), although these compounds generate high performance adsorbent materials but they are highly toxic (Leung 2001) therefore their application in the treatment of wastewater is impractical. Another type of mechanism is the ionic cross-linking, consisting in the formation of ionic bonds between the amino groups of Ch and the anions of the cross-linking agent (Jóźwiak et al. 2017). The main advantage of chitosan ionic cross-linking is that it generates materials with good chemical stability in acidic media (Crini et al. 2019) and the possibility of functionalizing the biopolymer material in the synthesis of 
biocomposite sorbents.

Dicarboxylic acids are used as ionic crosslinkers, in this case the oxalic acid (OA) has been used as a Ch cross-linking agent with low toxicity compared to other types of cross-linkers (Fadzallah et al., 2014; Jóźwiak et al., 2017) due to that OA is a natural compound in some plants (e.i black tea ) (Ghosh and Ali 2012).OA has a pKa=1.2, otherwise it dissociates in an aqueous medium into oxalate ions $\left(-\mathrm{C}_{2} \mathrm{O}_{4}^{2-}\right)$, these conditions cause the $\mathrm{Ch}$ to dissolve and reticule due to electrostatic interactions between the amino and oxalates groups (Fadzallah et al. 2014).

Cross-linked chitosan/oxalic acid hydrogels (ChOxb) have been used for the removal copper (II) (Mi et al. 2015) and Reactive Black 5 (Jóźwiak et al. 2017). Pérez-Calderón et al., (2020) reported the use of ChOxb for RR195 removal, increasing the adsorption capacity with respect to chitosan coacervated hydrogels (CP) (Pérez-Calderón et al. 2018).

Biocomposites matrices constituted by inorganic supports and Ch have been evaluated for the adsorption of synthetic dyes (Zhang et al., 2012; Barik et al., 2019). Biocomposites formulated with pure alumina and Ch crosslinked with oxalic acid have been developed and used for the adsorption of chromium (Boddu et al. 2003; Darjito et al. 2014) and fluorine (Li et al. 2013). There is scarce information concerning the combined use of inorganic materials such as alumina ceramic as a support for chitosan, where the adsorption of azo dyes occurs at the films surface.

The objectives of the present study were: a) to synthetize crosslinked oxalic acid-chitosan/ alumina ceramic biocomposite (BChA) for the adsorption of a reactive azo dye (RR195); b) to characterize the morphology and structure of BChA by using instrumental techniques such as Fourier transform infrared spectroscopy with attenuated total reflection (FTIR-ATR), Scanning electron microscopy with energy dispersive X-ray analysis (SEM-EDS), X-ray diffraction, thermogravimetric analysis, mercury inclusion porosimetry and Z-potential; c) to analyze the interactions present between the alumina ceramic support and the ionic cross-linked chitosan film; d) to determine the removal percentage and adsorption capacity in batch adsorption experiments under different experimental conditions; e) to test different equations for describing adsorption kinetics (Pseudo first order, Pseudo second order, Elovich, Intraparticle diffuson, and the mixed surface reaction and diffusion-controlled kinetic model; f) to obtain the adsorption isotherms and to select the appropriate model (Langmuir, Freundlich, Temkin, Redlich-Peterson or DubininRadushkevich) that best fits experimental results using regression analysis and statistical tests; $g$ ) to calculate thermodynamic parameters of the sorption process: enthalpy $(\Delta \mathrm{H})$, Gibbs free energy $(\Delta G)$ and entropy $(\Delta S) ; h)$ to evaluate the effect of different competitive ions present in the solution on the adsorption of the dye; i) to study the desorption process and regeneration of the biocomposite by applying adsorption/desorption cycles; j) to characterize the interactions between the biocomposite material and the RR195 dye, using different techniques: Z-potential; FTIR-ATR, SEMEDS. 


\section{Materials and methods}

\subsection{Reagents}

Chitosan was obtained from Sigma-Aldrich (St. Louis, MO, USA) in flake form. Using the potentiometric titration (Broussignac 1968) method the deacetylation degree was $79.5 \%(\mathrm{SD}=2.7)$ and $75.3 \%(S D=1.1)$ determined by FTIR method (Brugnerotto et al. 2001); the viscometric method using an Ostwald capillary viscometer allowed to determine the molecular weight which was $2.83 \times 10^{5} \mathrm{~g} \cdot \mathrm{mol}^{-1}$.

Oxalic acid dehydrated was obtained from BioPacK (Buenos Aires, Argentina). Reactive Red 195 (RR195) azo dye was provided by Chromeco S.A (Gral. Pacheco, Argentina), its molecular structure is shown Fig.A1 (Supplementary Information).

\subsection{Synthesis of the absorbent biocomposite material}

The crosslinked oxalic acid-chitosan/alumina ceramic biocomposite (BChA) was synthesized using ceramic particles alumina (CerPa) and cross-linked chitosan with oxalic acid (OA). Chitosan (Ch) solutions were prepared by mixing Ch flakes with $10 \%$ w. $\mathrm{V}^{-1}$ OA solution; two concentrations of Ch solution were prepared ( 2 and $1 \% \mathrm{~W} . \mathrm{v}^{-1}$ ). The solutions were stirred for $10 \mathrm{~h}$ at $55^{\circ} \mathrm{C}$, under these conditions the Ch was ionically cross-linked with the OA (Fadzallah et al. 2014; Mi et al. 2015; PérezCalderón et al. 2020).

CerPa were formulated with 75 wt \% alumina, 20 wt \% bauxite, 2 wt $\%$ kaolin and 2 wt $\%$ talc as support material. CerPa were synthesized using an Eirich High Intensity Mixer Machine (Model R20E, Erich Industrial Ltd., Brazil) where the two process steps, mixing and granulating, are performed in the same equipment.

The particles were obtained through batch experiments where the material and water were combined to form a homogeneous mixture and the spherical geometry was achieved by adjusting the speed of the mixing tool. The particles were sieved to obtain diameters between 14 and 16 ASTM meshes (diameters between 1.18-1.40 mm). The CerPa were dried in a conventional oven and calcined at $1500^{\circ} \mathrm{C}$ for $2 \mathrm{~h}$ in a high temperature oven MHI (USA). The lack of RR195 adsorption capacity of CerPa was tested by mixing CerPa and RR195; this experiment corroborated that this individual material did not show adsorption properties.

BChA was prepared by coating the CerPa with the cross-linked chitosan solution. The coating capacity of CerPa was directly related to the presence of alumina in the inorganic material; this assumption was corroborated by formulating CerPa without alumina and observing in this case that film-forming capacity was weak and the biopolymer detached from the CerPa after being in contact in a solution. The method described by Boddu et al.,(2003) was implemented with the following modifications: (i) Dried CerPa was activated by stirring the particles in a OA $10 \% \mathrm{w} \cdot \mathrm{v}^{-1}$ solution for 4 $h$ at $25^{\circ} \mathrm{C}$, after this step the material was filtered and washed with distilled water; finally the activated CerPa was dried in a vacuum oven LiTekvo model DZF-6030A (LiTekvo Instruments, Minhang 
District, Shanghai, China) at $70^{\circ} \mathrm{C}$ and reduced pressure of $100 \mathrm{mmHg}$ to a constant dry weight. (ii) The activated CerPa was mixed with $1 \% \mathrm{w} \cdot \mathrm{v}^{-1}$ cross-linked chitosan solution under constant shaker stirring at $25^{\circ} \mathrm{C}$ for $17 \mathrm{~h}$. To finish the first coating, the material was dried at $55^{\circ} \mathrm{C}$ in a Heratherm OMS 60 forced convection oven (Thermo Scientific, Germany) for $24 \mathrm{~h}$. (iii) The second coating was performed by mixing the product of the previous step with $2 \% \mathrm{w}^{-1} \mathrm{v}^{-1}$ cross-linked chitosan solution under constant stirring at $25^{\circ} \mathrm{C}$ for $17 \mathrm{~h}$. The excess of filmogenic solution was removed; in addition it was neutralized with $1 \mathrm{~N}$ sodium hydroxide, standing for $3 \mathrm{~h}$ for subsequent washing with distilled water until neutral, obtaining the BChA. (iiv) BChA was dried at $55^{\circ} \mathrm{C}$ for $24 \mathrm{~h}$ in a forced convection oven.

The amount of biopolymer in the BChA was determined by weight loss after calcination of the biocomposite at $750^{\circ} \mathrm{C}$ for $10 \mathrm{~h}$ using a muffle. The test was performed in triplicate and the results were expressed as a percentage of cross-linked chitosan coating (\% CCh) calculated according to Eq.1:

$$
\% \mathrm{CCh}=\frac{\mathrm{w}_{\mathrm{m}}-\mathrm{W}_{\mathrm{c}}}{\mathrm{w}_{\mathrm{m}}} \times 100
$$

where $W_{m}$ is the mass of the dry sample and $W_{c}$ of the ashes. This information is important to express the amount of adsorbent in terms of the active material during the adsorption process.

\subsection{Characterization of bio-composite}

Characterization of $\mathrm{BChA}$ and the materials used in this work were performed using: Fourier transform infrared spectroscopy with a attenuated total reflection accessory (FTIR-ATR), scanning electron microscopy equipped with energy dispersive X-ray spectrometry (SEM-EDS), X-ray diffraction (XDR), Thermogravimetric analysis (TGA) and Z-Potencial (ZP).

FTIR-ART was carried out using a Thermo Nicolet iS10 spectrometer (Thermo Scientific, MA, U.S.A). FTIR Spectra were obtained in \%Transmittance mode with $4 \mathrm{~cm}^{-1}$ spectral resolutions and 34 scans. ATR accessory consisted of diamond crystal (nominal angle of incidence $\left.=42^{\circ}\right)$. XRD was performed on sample powders; diffractograms were obtained using an X-ray diffractometer Philips PW-3710 using Cu-Ka radiation and $\mathrm{Ni}$ at constant voltage $(40 \mathrm{kV}, 35 \mathrm{~mA})$. TGA was performed with a thermogravimetric analyzer Rigaku (Thermo Plus EVO2, Osaka, Japan) using $\mathrm{N}_{2}$ with inert gas. Surface morphology was studied using SEM-EDS, therefore a NeoScope Benchtop JEOL JCM-6000 microscope (JEOL, U.S.A) equipped with energy dispersion spectrometry X-ray (EDS) unit JEOL WX-36210DPP was employed.

ZP was measured to characterize the surface charges of the material; a nanoparticle analyzer SZ-100-Z (Horiba Instruments Inc., Kyoto, Japan) provided with a laser diode model JUNO 10G-HO (Showa Optronics Co., Ltd., Yokohama, Japan) operating at $532 \mathrm{~nm}$ was used. ZP of the material was determined by using a solution containing grinded BChA with an electrode cell (carbon, $6 \mathrm{~mm}$ ); $\mathrm{ZP}$ was reported as the average of five determinations per sample. The isoelectric point $\left(\mathrm{pH}_{\mathrm{IEP}}\right)$ of 
183

184

185

186

187

188

189

190

191

192

193

194

195

196

197

198

199

200

201

202

203

204

205

206

207

208

209

210

211

212

213

214

215

216

the material was established by means of the ZP determined at different pH (Pérez-Calderón et al. 2020).

Microstructural properties such as pore size distribution and specific surface were determined by mercury intrusion porosimetry using a porosimeter Pascal 440 (Thermo Fischer Scientific, Belgica). The mean diameter of the biocomposite and the layer of the cross-linked chitosan was determined by analyzing at least fifty micrographs of BChA using a MZ-10F stereomicroscope with DFC490 camera (Leica Microscopy Ltd, Germany) that were processed using the Image-J software.

\subsection{Batch adsorption studies}

Batch assays were carried out for the adsorption of RR195 onto the crosslinked oxalic acidchitosan/alumina ceramic biocomposite (BChA) varying: dosage of the biocomposite (0.43-4.25 g.L' $\left.{ }^{1}\right), \mathrm{pH}(2-12)$ and contact time (0-24 h). Initial concentration ( $\left.\mathrm{C}_{0}\right)$ and dye solution volume were 150 $\mathrm{mg} \cdot \mathrm{L}^{-1}$ and $0.02 \mathrm{~L}$, respectively. The initial $\mathrm{pH}$ of the dye solution was adjusted with hydrochloric acid and sodium hydroxide $0.1 \mathrm{M}$; an orbital shaker with temperature control, was used to maintain constant conditions during the experiment (125 rev. $\left.\mathrm{min}^{-1}, 298 \mathrm{~K}\right)$. The final dye concentration $\left(\mathrm{C}_{\mathrm{f}}\right)$ was determined by UV-visible spectrophotometry using Hach DR-2800 spectrophotometer (Loveland, Colorado, USA) at a wavelength of $538 \mathrm{~nm}$.

The results were evaluated by determining the percentage of dye removal (\%RE) and the adsorption capacity $(\mathrm{Q})$ at a given time $t\left(Q_{t}\right)$ using Eq. 2 and Eq.3.

$$
\begin{gathered}
\% \mathrm{RE}=\frac{\mathrm{C}_{0}-\mathrm{C}_{\mathrm{f}}}{\mathrm{C}_{0}} \times 100 \\
\mathrm{Q}_{\mathrm{t}}=\frac{\left(\mathrm{C}_{0}-\mathrm{C}_{\mathrm{t}}\right)}{\mathrm{W}} \times \mathrm{V}
\end{gathered}
$$

where $C_{t}$ is the concentration at a given time $t, V$ is the volume of the solution $(L)$ and $W$ is the dose of $\mathrm{BChA}(\mathrm{g})$ in terms of the mass of coating using the cross-linked chitosan.

Under equilibrium conditions, the percentage removal ( $\% \mathrm{RE}_{\mathrm{e}}$ ) was calculated using Eq.2 by replacing $C_{f}$ with $C_{e}$ (equilibrium concentration) and the adsorption $\left(Q_{e}\right)$ was calculated using Eq.3 by replacing $C_{t}$ with $C_{e}$.

\subsection{Kinetics, adsorption Isotherms and thermodynamic studies}

The assays were carried out using the doses that achieved the best adsorption performances. Moreover, different $\mathrm{pH}$ values were tested to evaluate the cross-linking effect of chitosan on the chemical stability of the biocomposite. The equations used for kinetics, isotherm and thermodynamic studies are shown in Table 1 (Eqs. 4 to 12).

Kinetic studies were carried out using different $C_{0}$ of RR195 (100, $\left.200 \mathrm{mg} . \mathrm{L}^{-1}\right)$; the dye concentration was determined at different tested times $\left(C_{t}\right)$ in order to calculate $Q_{t}$ using Eq.3. The kinetic models tested were Pseudo first order (Ps1 Eq.4), Pseudo second order (Ps2 Eq.5), Elovich (Eq.7), Intraparticle diffusion (Eq.8) and the Mixed surface reaction (Eq.9) and diffusion-controlled 
kinetic model (MSR-DCK Eq.10).

The adsorption isotherms studies were tested at different initial concentrations of RR195 $\left(C_{0}=70\right.$ $\left.500 \mathrm{mg} \cdot \mathrm{L}^{-1}\right), \mathrm{Q}_{\mathrm{e}}$ was determined using Eq.3 by replacing $\mathrm{C}_{t}$ with $\mathrm{C}_{\mathrm{e}}$ (equilibrium concentration). Different models (Table 1) were used to evaluate the adsorption equilibrium conditions of the biocomposite (Langmuir (Eq.13), Freundlich (Eq.15), Temkin (Eq.16), Redlich-Peterson (R-P Eq.17), and Dubinin-Radushkevich (D-R Eq.18)).

To determine the thermodynamic parameters the sorption isotherms were determined at different temperatures (298, 308 and $318 \mathrm{~K})$. Using Van't Hoff equation (Eq.21) the enthalpy $(\Delta H)$ and entropy $(\Delta S)$ were calculated. In this case, equilibrium partition constant $\left(K_{P}\right)$ was obtained in order to determine the thermodynamic parameters (Zhang et al. 2014; Tran et al. 2017; Pérez-Calderón et al. 2018, 2020). K $K_{P}$ was estimated as described in Pérez-Calderón et al., (2020, 2018); K (Eq.22 in Table 1)) considers the ratio between the activity of the dye adsorbed by the solid $\left(\mathrm{a}_{\mathrm{s}}\right)$ and the activity of the dye in the solution at equilibrium $\left(\mathrm{a}_{\mathrm{e}}\right)$. Another possibility is to express $\mathrm{K}_{\mathrm{P}}$ in terms of the ratio between activity coefficients $(\gamma)$; in this case $K_{P}$ is the ratio between the activity coefficient of the adsorbed dye $\left(\gamma_{s}\right)$ and the activity coefficient of the dye in the solution at equilibrium $\left(\gamma_{e}\right)$. If $\gamma$ is used, the adsorbed dye concentration ( $\mathrm{C}_{\mathrm{s}}$ Eq.24) and the dye concentration in equilibrium $\left(\mathrm{C}_{\mathrm{e}}\right)$ must be considered.

The activity coefficient $(\gamma)$ approaches unity when the $\left(C_{s}\right) \rightarrow 0$ and $\left(C_{e}\right) \rightarrow 0$, therefore Eq.22 can be written as Eq.23, plotting $\operatorname{Ln}\left(C_{s} / C_{e}\right)$ vs $C s$ and extrapolating to $C_{e} \rightarrow 0 ; K_{p}$ was calculated at each experimental temperature (Tran et al.,2017). The Gibbs free energy $(\Delta \mathrm{G})$ was calculated using Eq.25.

\subsection{Regeneration of the Biocomposite and Effect of Competitive lons}

Consecutive cycles of desorption/adsorption were conducted; for the regeneration stage, RR19 was desorbed from the BChA used in a previous adsorption experiment with an initial dye concentration of $\mathrm{C}_{0}=200 \mathrm{mg} \cdot \mathrm{L}^{-1}$. BChA was kept in contact with Milli-Q water $(0.020 \mathrm{~L})$ at highly alkaline conditions $(\mathrm{pH}=12)$, and the test was performed at a constant agitation and temperature.

The regenerated biocomposite material was dried in a forced convention oven at $55^{\circ} \mathrm{C}$ until constant weight and submitted to adsorption cycles with a RR195 initial concentration of $\mathrm{C}_{0}=200$ $\mathrm{mg} \cdot \mathrm{L}^{-1}(\mathrm{~V}=0.020 \mathrm{~L})$; in this way three adsorption cycles were completed with two intermediate desorption cycles.

The presence of inorganic ions was analyzed in the adsorption process by evaluation of \%RE, the tested ions were: $\mathrm{Cl}^{-}$and $\mathrm{NO}_{3}^{-}$, at a concentration of $5 \mathrm{mmol} \cdot \mathrm{L}^{-1}$; in all cases the solutions were prepared with Milli-Q water. For the assays the $C_{0}$ of dye was $200 \mathrm{mg} \mathrm{L}^{-1}$ and the salts used were $\mathrm{KCl}$ and $\mathrm{KNO}_{3}$.

\subsection{Statistical analysis}

For the batch adsorption assays the equilibrium isotherms, kinetic equations and thermodynamic 
parameters were evaluated from linear and non-linear regressions using Origin-Pro 8 software (Origin Lab Corporation, Northampton, Ma., U.S.A.) The goodness of fit was evaluated taking into account the determination coefficient $\left(R^{2}\right)$, mean average perceptual error (MAPE) and chi-square distribution error $\left(\chi^{2}\right)$; MAPE and $\chi^{2}$ were determined with the Eqs.26 and 27 respectively, where $y_{e}$ is the experimental value and $y_{p}$ is the value predicted by the model.

$$
\begin{gathered}
\text { MAPE }=\frac{\sum\left|\left(\mathrm{y}_{\mathrm{e}}-\mathrm{y}_{\mathrm{p}}\right) / \mathrm{y}_{\mathrm{e}}\right|}{\mathrm{n}} \times 100 \\
\chi^{2}=\sum \frac{\left(\mathrm{y}_{\mathrm{e}}-\mathrm{y}_{\mathrm{p}}\right)^{2}}{\mathrm{y}_{\mathrm{p}}}
\end{gathered}
$$

The analysis of variance (ANOVA) was conducted to assess significant differences between the samples; means were compared by a Fisher LSD test using a 95\% confidence level (significant difference, $P \leq 0.05)$.

\section{Results and Discussion}

\subsection{Characterization of the Biocomposite}

\subsubsection{Surface properties and morphology}

The mean diameter of crosslinked oxalic acid-chitosan/alumina ceramic biocomposite (BChA) and alumina ceramic particles (CerPa) was $1.35 \mathrm{~mm}(\mathrm{SD}=0.98)$ and $1.18 \mathrm{~mm}(\mathrm{SD}=0.35)$, respectively; these values were obtained from micrographs (Fig.1a-b) of the materials, which were analyzed using Image-J software. Micrographs of the surface morphology of CerPa and BChA obtained by SEM before the adsorption process are shown in Fig.1a-b. SEM micrograph of BChA (Fig.1b) showed the presence of chitosan (Ch) evidenced by a smoother and softer surface of the biocomposite compared with the surface of CerPa (Fig.1a). The surface morphology of the BChA was attributed to the cross-linked Ch film that coated the surface of the ceramic particle. EDS microanalysis spectrum (Fig. 1b) shows that the surface of BChA contained oxygen (O), carbon (C), nitrogen $(\mathrm{N})$ and aluminum $(\mathrm{Al})$. The weight percentage of $\mathrm{C}$ in $\mathrm{BChA}$ was $28.57 \%$, being this value higher than in CerPa (8.26\%, Fig.1a). In addition the EDS spectrum of BChA showed the presence of $\mathrm{N}$, due to the cross-linked chitosan coating $(\mathrm{ChC})$ on the ceramic material.

Surface microstructural properties were determined by mercury intrusion porosimetry; the pore size diameter determined was $1165.2 \mathrm{~nm}$ for CerPa and $394.5 \mathrm{~nm}$ for BChA and the specific surface area of these materials were $0.496 \mathrm{~m}^{2} \cdot \mathrm{g}^{-1}$ and $1.42 \mathrm{~m}^{2} \cdot \mathrm{g}^{-1}$ for CerPa and BChA, respectively. The increase in the specific surface of the biocomposite is attributed to the cross-linked chitosan coating over the surface (micropores and crevices) of CerPa; similar results were reported Zhang et al., (2012).

The amount of biopolymer that is coating the CerPa was determined by calcination of $\mathrm{BChA}$, and the results were expressed as percentage cross-linked chitosan coating (\%CCh). According to Eq.1, $\%$ CCh was $1.7 \%(S D=0.4)$, this result is important since it is the amount of active sorbent material 
that generates interactions with dye molecules.

\subsubsection{Structural characterization}

\subsubsection{FTIR-ATR analysis}

FTIR-ATR spectra of Ch, OA, CerPa and BChA are observed in Fig.1 c-d. Previous studies describe the results of Ch (Pérez-Calderón et al. 2018, 2020) and OA (Pérez-Calderón et al., 2020 ) spectra; an overview of the bands characteristics is shown in Table A1 (Supplementary information).

The characteristic bands of CerPa (Fig.1d) were located: a) at $653 \mathrm{~cm}^{-1}$ for the $\mathrm{O}-\mathrm{Al}-\mathrm{O}$ bending (Li et al.,2013); b) at $824 \mathrm{~cm}^{-1}$ for the $\mathrm{Al}-0$ stretching (Jagtap et al.,2011); (c) at 625,1318 and 1096 $\mathrm{cm}^{-1}$ characteristics for alumina (Jagtap et al.,2011); in addition, bands between $500-1000 \mathrm{~cm}^{-1}$ characteristic for aluminum oxides (Jagtap et al.,2011) were observed.

OA was used to bind the alumina of the CerPa and Ch; BChA was synthesized by (i) activation of CerPa with $O A$ and (ii) coating with an ionic modified Ch solution. Different chemical reactions are generated in these stages. In the first stage, the use of OA generates the esterification reaction between the alumina of the CerPa and the oxalate ion, producing the alumina oxalate (III) complex (Boddu et al.,2003; Dobson and McQuillan, 1999); this reaction is represented in Fig.2a. Fig.1d shows in the spectrum of BChA, the presence of the band at $1723 \mathrm{~cm}^{-1}$ characteristic of the stretching of $-\mathrm{C}=\mathrm{O}$ group of the ester group confirming the presence of this type of bond.

In the second stage, an electrostatic interaction between the alumina oxalate (III) complex and the protonated free amino groups of Ch (Boddu et al.,2003; Darjito et al., 2014) occurs, being this reaction represented in Fig. $2 b$. Results show the chemical interaction between the different constituents (inorganic support and biopolymer) of the new synthesized biocomposite generates an active and stable matrix.

The coating of the CerPa was carried out using ionic crosslinked chitosan where the ionic interaction occurs between the carboxylate anions of $\mathrm{OA}$ and the protonated amino group of the $\mathrm{Ch}$ (Pérez-Calderón et al. 2020).

Fig.1d shows the existence of oxalic/chitosan ion cross-linking was evidenced: a) at $1685 \mathrm{~cm}^{-1}$ band shift of the symmetric stretching of the carboxylic group originally present at $1698 \mathrm{~cm}^{-1}$ of the OA spectrum (Mi et al.,2015); b) at $1517 \mathrm{~cm}^{-1}$ the shift and deformation of the band of the amino group originally overlapped at $1550 \mathrm{~cm}^{-1}$, due to the ionic interaction of the protonated amino group of the chitosan molecule with the carboxyl anions of the OA (Fadzallah et al.,2014; Mi et al.,2015; Pérez-Calderón et al.,2020); the reaction is represented in Fig. 2c. Fig.1d, confirms the presence of Ch in BChA; the observed bands were: a) at $2951 \mathrm{~cm}^{-1}$ and $2885 \mathrm{~cm}^{-1}$ the symmetrical stretching of the $-\mathrm{CH}$ aliphatic and vibration of the $\mathrm{C}-\mathrm{H}$ tensions, respectively; b) at $1065 \mathrm{~cm}^{-1}$ and $1027 \mathrm{~cm}^{-1}$ the bands correspond to the vibrations of the stretching of the $-\mathrm{C}-\mathrm{OH}$ group characteristic of polysaccharides. In addition, in the spectrum of the $\mathrm{BChA}$, the band at $1397 \mathrm{~cm}^{-1}$, which is 
characteristic of the asymmetric stretching of $-\mathrm{C}=0$ provided by the $\mathrm{OA}$, and at $659 \mathrm{~cm}^{-1}$, the $-\mathrm{Al}-$ $0-$ Al bending, were observed.

\subsubsection{XDR and TGA analysis}

Fig.1e shows the diffractograms for CerPa and BChA. For CerPa it was confirmed that the predominant phase was $\alpha$-alumina due to the presence of several diffraction peaks at $2 \theta=25.59^{\circ}$,

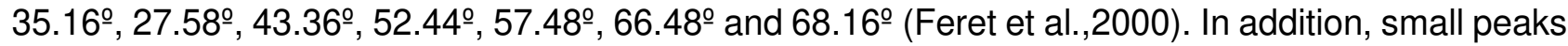
were observed at $2 \theta=36.84^{\circ}, 59.56^{\circ}$ and $64.94^{\circ}$ that are of spinel $\left(\mathrm{MgAl}_{2} \mathrm{O}_{4}\right)$ and at $22.24^{\circ}$ due to cristobalite $\left(\mathrm{SiO}_{2}\right)$; this was corroborated with results obtained by EDS microanalysis presented in Fig.1a showing the existence of magnesium (Mg) and silicon (Si).

For BChA, the characteristic diffraction peaks of the CerPa were observed. In addition, three new peaks were presented in the positions $2 \theta=14.42^{\circ}, 24.69^{\circ}$ and $30.30^{\circ}$, attributed to the $\mathrm{OA} / \mathrm{Ch}$ crosslinking (Mi et al. 2015).

The TGA curves of $\mathrm{Ch}, \mathrm{OA}$ and BChA are shown in Fig.1f. For Ch, a weight loss was observed at $100^{\circ} \mathrm{C}$, typical of water release. Weight losses occurred also at $277^{\circ} \mathrm{C}$ and $642^{\circ} \mathrm{C}$, that are characteristic of the total melting and decomposition of the biopolymer (Rekik et al., 017). OA TGA curve showed at $143^{\circ} \mathrm{C}$ a distinct weight loss attributed to the complete dehydration of the sample (Mi et al. 2015); at $173^{\circ} \mathrm{C}$, unstable intermediates such as $\mathrm{H}_{2} \mathrm{O}$, $\mathrm{CO}$ and $\mathrm{CO}_{2}$ are released, and finally at $214^{\circ} \mathrm{C}$ the total decomposition of the $\mathrm{OA}$ is produced.

For BChA an initial weight loss attributed to the release of water is shown; subsequently at 244 ${ }^{\circ} \mathrm{C}$ the thermal event is due to the rupture of the electrostatic interaction in the ionic cross-linking of $\mathrm{Ch}$ with $\mathrm{OA}$ (Mi et al. 2015). The weight loss at $458^{\circ} \mathrm{C}$ can be attributed to the breakdown of the ester bond of the alumina (III) oxalate complex, and finally at $638^{\circ} \mathrm{C}$ the total weight loss characteristic of biopolymer fusion occurred. The percentage of total weight loss for the BChA corresponded to $2.04 \%$; this is comparable to the \%CCh determined by weight loss the biocomposite from calcination $(\% \mathrm{CCh}=1.7)$.

\subsection{Experimental adsorption conditions: Effect of time, doses and pH}

The removal of RR195 using BChA was analyzed and the effect of contact time on $Q$, testing different sorbent doses is shown in Fig. 3a. $Q$ increased with time achieving asymptotic values at equilibrium $\left(Q_{e}\right)$; at this condition, the amount of dye that is adsorbed is in a dynamic equilibrium state with the amount of dye that is desorbed from the sorbent (Li et al. 2013). Fig. 2a shows that for concentrations ranging between 0.85 and $4.25 \mathrm{~g} \cdot \mathrm{L}^{-1}$ the equilibrium was achieved after $15 \mathrm{~h}$, however using the lowest dose $\left(0.43 \mathrm{~g}^{\mathrm{L}} \mathrm{L}^{-1}\right)$ this equilibrium condition was not reached even after 25 h. Fig.3b shows $\% R E_{e}$ and $Q_{e}$ as functions of sorbent doses; non-significant differences in $\% R E_{e}$, were found for sorbent doses ranging between 0.85 and $4.25 \mathrm{~g} . \mathrm{L}^{-1}$, therefore the lowest dose $(0.85$ g. $\mathrm{L}^{-1}$ ) was chosen to be used in the subsequent studies, because it led to the highest $\mathrm{Q}_{\mathrm{e}}$.

Fig. $3 \mathrm{c}$ shows the variation of the $\% \mathrm{RE}_{e}$ dye with $\mathrm{pH}$. The $\mathrm{pH}$ of the solution influences the degree 
of protonation of the sorbent, thus determining the specific charge of the binding sites and the absorption performance of the sorbent (Crini et al. 2019). Pérez-Calderón et al.,(2020, 2018) reported that RR195 adsorption was favored by using chitosan-based sorbent materials, under acidic conditions $(\mathrm{pH}<4)$; this is due to the electrostatic attraction between the positive charged surface of the material by protonation of the free amino groups $\left(\mathrm{NH}_{3}^{+}\right)$of the chitosan and the sulfonated $\left(-\mathrm{SO}_{3}^{-}\right.$ ) groups of RR195 (Crini and Badot, 2008).

Fig.3c shows that the highest $\% \mathrm{RE}_{e}$ was at $\mathrm{pH}=2\left(\% \mathrm{RE} \mathrm{E}_{\mathrm{e}}=91.33 \mathrm{SD}=0.15\right)$. The ability to adsorb at this very low $\mathrm{pH}$ condition can be attributed to the stable structure of the biopolymer gained by the ionic cross-linking of $\mathrm{Ch}$ with OA which avoids the solubilization of the biopolymer (Gonçalves et al. 2019). Pérez-Calderón et al., $(2020,2018)$ reported that the maximum adsorption of RR195 onto $\mathrm{ChOxb}$ and $\mathrm{CP}$ materials was at $\mathrm{pH}=4$. In comparison, crosslinked chitosan bond to the ceramic material $(\mathrm{BChA})$ showed maximum adsorption at $\mathrm{pH}=2$ resulting in a material with better adsorption performance and mechanical stability. The reasons for this improvement are the larger exposed active surface of the material and the increase of the number of free amino groups allowing them to interact more effectively with the sulfonic groups of the dye (Li et al., 2013).

Since the $\mathrm{pK}_{\mathrm{a}}$ of chitosan is 6.5 , at $\mathrm{pH}>6.5$ the amino groups are not likely to be protonated and the adsorption process of the anionic azo dye will not be favored which in turn will decrease the $\% \mathrm{RE}_{\mathrm{e}}$. At $\mathrm{pH}>7$ the existence of electrostatic repulsion forces between the dye anions and the unprotoned surface of the adsorbent causes the further decrease of the \%RE

In order to know the isoelectric point $\left(\mathrm{pH}_{\mathrm{IEP}}\right)$ of $\mathrm{BChA}$, the change of Z-potential (ZP) at different $\mathrm{pH}$ values before and after removal was studied (Fig $3 \mathrm{c}$ ). According to the results obtained, the $\mathrm{pH}_{\text {IEP }}$ was between $\mathrm{pH}$ 6-7 before and after adsorption; in this range, the biocomposite has a surface charge near to neutrality. In BChA, the decrease of ZP, after the adsorption shows that the amino groups of the material interact electrostatically with the dye molecules (Pérez-Calderón et al. 2020).

\subsection{Interaction between the biocomposite and the RR195 dye}

The interaction between the sorbent material (BChA) and the dye was analyzed. Fig.4a shows the micrograph obtained by stereomicroscopy, and the characteristic color of the dye can be observed at the surface of the BChA. The EDS microanalysis spectrum at the surface of the BChA after adsorption (Fig.4b) shows the presence of sulfur (S), corroborating the existence of RR195 interacting with BChA.

Fig.4c shows a cross-section of BChA after adsorption, in which it was possible to observe the dye adsorbed on the coated CerPa from the image analysis using Image-J; the thickness of the attached film was $7.23 \mu \mathrm{m}(\mathrm{SD}=0.6)$.

FTIR-ART transmission spectra of the material after adsorption process (BChA+RR195) is shown in Fig.4d; the FTIR-ATR spectra of the RR195 dye is shown in Fig.A2 (Supplementary Information) and the analysis of the main bands is described in Table A2 (Supplementary Information). 
The main changes in the BChA+RR195 (after adsorption) spectra with respect to BChA were the presence and changes of the following bands : a) at $3455 \mathrm{~cm}^{-1}$ due to high interactions of hydrophilic nature (stretching groups $-\mathrm{NH},-\mathrm{OH}$ and the resonant aromatic structure $=\mathrm{CH}$ of the dye); b) the reduced intensity of the band at $1517 \mathrm{~cm}^{-1}$, can be attributed to electrostatic interactions and/or hydrogen bonds between the amino groups of chitosan and ionic sulfonated groups of the dye (Wang et al. 2016); c) at $1319 \mathrm{~cm}^{-1}$ due to the $S=0$ vibrations of $\mathrm{SO}_{2}$ group of the dye molecule; $d$ ) at 1612 $\mathrm{cm}^{-1}$ corresponding to the vibrational stretching of the aromatic cycle of the dye (this band was originally located at $1617 \mathrm{~cm}^{-1}$ in the spectrum of the dye (Fig.A2)).

As was mentioned in section 3.2.1, changes in $\mathrm{pH}_{\text {IEP }}$ were not observed before and after adsorption, therefore it can be concluded that the interactions were of an electrostatic nature $\left(\mathrm{NH}_{3}^{+}\right.$--- $\mathrm{SO}_{3}^{-}$) between biocomposite and dye (Liu and Zhang 2015; Pérez-Calderón et al. 2018, 2020).

\subsection{Adsorption Kinetics}

Adsorption kinetics assays were carried out using a dose of $0.85 \mathrm{~g} \cdot \mathrm{L}^{-1}$ of biocomposite and different initial dye concentrations $\left(\mathrm{C}_{0}=100,200 \mathrm{mg} \cdot \mathrm{L}^{-1}\right)$. In order to study the effect of $\mathrm{pH}$ on the adsorption kinetics, experiments at $\mathrm{pH}=2$ and 4 were conducted. Results of the adsorption kinetics are depicted in Fig.5 a-b, showing that after 17h equilibrium conditions were established for both $\mathrm{pH}$ values and $\mathrm{C}_{0}$ tested; the maximum adsorption performance was reached at $\mathrm{pH}=2.5\left(\mathrm{Q}_{\mathrm{e}}(17 \mathrm{~h})=\right.$ $\left.203.98 \mathrm{mg}^{-1} \mathrm{~g}^{-1}(\mathrm{SD}=2.4) \mathrm{C}_{0}=200 \mathrm{mgL}^{-1}\right)$, with an increase in the removal capacity compared to $\mathrm{pH}=4$ $\left(Q_{\mathrm{t}}(17 \mathrm{~h})=176.01(\mathrm{SD}=0.45) \mathrm{g} \cdot \mathrm{L}^{-1} \mathrm{C}_{0}=200 \mathrm{mg} \cdot \mathrm{L}^{-1}\right)$ but not in the rate of the process. Results confirm that under conditions of high acidity $(\mathrm{pH}=2)$ protonation of the free amino groups in the matrix generates a significant increase of the adsorption capacity.

Different kinetic equations (Table 1) were tested and corresponding parameters were calculated from non-linear regressions. Experimental results were analyzed by Pseudo First Order (Ps1; Eq.(4)), Pseudo Second Order (Ps2; Eq.(5)), Elovich (Eq.(7)), Intraparticle Diffusion (Eq.(8)) and Mixed Diffusion and Adsorption Model (MSR-DCK; Eq.(9)).

Pseudo first order (Ps1, Eq.4 Table 1) and Pseudo second order equation (Ps2, Eq5 Table 1) are often used to model adsorption kinetics. Elovich's empirical model (Eq.7 Table 1) is used to describe mechanisms of chemisorption. In Eq.7 the constants $\alpha_{\mathrm{E}}$ is the initial adsorption rate related to chemisorption; and $\beta_{E}$ is desorption rate constants at the surface coverage. The intraparticle diffusion model (Eq.8 Table 1) describes two regions corresponding to: surface adsorption (rapid external diffusion) and intra-particle diffusion stage (Weber and Morris 1963).

The MSR-DCK model (Haerifar and Azizian 2013) considers that the diffusion of the dye molecules in the sorbent and its adsorption in the active sites of the biocomposite occur simultaneously, the analytical solution (Eq.9 Table 1) was reported by Haerifar and Azizian (2013); where the relative equilibrium uptake $\left(w_{e q}\right)$ is $0 \leq w_{e q} \leq 1$. The effect of diffusion was introduced by the coefficient b (Eq.12 Table 1). 
The obtained model parameters are shown in Table 2. Goodness of fit was evaluated using the determination coefficient $\left(\mathrm{R}^{2}\right)$, mean average perceptual error (MAPE; Eq.26) and chi-square distribution error ( $\chi^{2}$; Eq.27).

Analyzing the fitting of the non-linear regressions $\mathrm{R}^{2}$, MAPE and $\chi^{2}$; it can be concluded that Ps2 model provided the best fit with the experimental data.

According to the results of Fig.5 a-b, the experimental $Q_{e}$ values were $109.92 \mathrm{mg} \cdot \mathrm{g}^{-1}(\mathrm{SD}=1.8)$ and $203.98 \mathrm{mg} \cdot \mathrm{g}^{-1}(\mathrm{SD}=2.4)$, at $\mathrm{pH}=2$ for $\mathrm{C}_{0}$ values of 100 and $200 \mathrm{mg} \cdot \mathrm{L}^{-1}$ respectively; at $\mathrm{pH}=4$ the obtained values of $Q_{e}$ were $103.53 \mathrm{mg} \cdot \mathrm{g}^{-1}(S D=0.13)$ and $176.01 \mathrm{mg} \cdot \mathrm{g}^{-1}(S D=0.45)$, respectively.

According to Eq.6, $t / Q_{t}$ vs time was plotted for each $C_{0}$. Fig.A3 (Supplementary Information) shows that a completely linear relationship was obtained, so it can be concluded that the removal process is controlled only by adsorption (Haerifar and Azizian 2013). Zhang et al.,(2012) reported that for methyl orange adsorption using unmodified $\mathrm{Ch}$ /alumina biocomposite the model that best fit was Ps2.

\subsection{Adsorption isotherms}

The isothermal equations that have been tested in the present work are shown in Table 1: Langmuir (Eq.13), Freundlich (Eq.15), Temkin (Eq.16), Redlich-Peterson (RP, Eq.17), DubininRadushkevich (DR, Eq.18), in order to know the maximum adsorption capacity. The isotherms were analyzed at $\mathrm{pH} 2$ and 4 and the results are shown in Fig.5 c-d.

Langmuir model (Eq.13 Table 1) assumed that adsorption occurs in a single layer and can occur explicitly at a finite (fixed) number of specific localized sites, without any lateral interaction and without steric hindrance between the adsorbed molecules (Vijayaraghavan et al. 2006). The maximum adsorption capacity $\left(\mathrm{Q}_{\mathrm{m}}, \mathrm{mg} \cdot \mathrm{g}^{-1}\right)$ and the affinity of the adsorbate for the adsorbent $\left(\mathrm{K}_{\mathrm{L}}\right.$, L.mg-1) were calculated (Eq.13). $Q_{m}$ was evaluated at different temperatures showing that higher temperatures favored the adsorption process

Table 3 shows the results obtained for this model, $\mathrm{Q}_{\mathrm{m}}$ at $298 \mathrm{~K}$ and $\mathrm{pH}=2$ was $333.9 \mathrm{mg} \cdot \mathrm{g}^{-1}$ and for $\mathrm{pH}=4$ the value of $\mathrm{Q}_{m}$ was $254.3 \mathrm{mg} \cdot \mathrm{g}^{-1}$. These results show the advantages of using a crosslinked Ch with $\mathrm{OA}$ since it increased the adsorption capacity at a very low $\mathrm{pH}$, because the coating also stabilized the structure of the BChA avoiding biopolymer solubilization. Moreover, according to these results, $Q_{m}$ is the highest reported for RR195 removal in comparison with other sorbents materials. Table 4 shows different adsorbents used for the removal of RR195 in decreasing order of $Q_{m}$. As can be seen, BChA is the material with the best adsorption capacity for the RR195 removal.

Several authors have used the separation factor $\left(R_{L}\right)$ to analyze the results of Langmuir's model. $R_{L}$ was calculated using the Eq.14 (Table 1) which takes into account the constant $\left(K_{L}\right)$ determined from the non-linear regression of Eq.13 and the initial concentration $\left(C_{0}\right)$. $R_{L}$ value indicates the adsorption nature to be either unfavorable $\left(R_{L}>1\right)$, linear $\left(R_{L}=1\right)$, favorable $\left(0<R_{L}<1\right)$ or irreversible $\left(R_{L}=0\right)$ (Zhang et al., 2014); according to the results shown in Table 3 for the different tests the 
process is favorable.

On the other hand, plotting $R_{L}$ vs $C_{0}$ (Fig.A4 a-b; Supplementary Information) the $R_{L}$ values decreased with respect to the increase of the initial dye concentration, this indicates that the process was favored at high initial dye concentrations (Zhang et al. 2014).

Freundlich model considers a heterogeneous adsorption surface of the adsorbent (Freundlich 1906). The equation that represent Freundlich's model (Eq.15) is presented in Table 1. The parameters of this model are the adsorption capacity coefficient $K_{F}\left(\left(m g \cdot g^{-1}\right)(m g . L)^{-1 / n}\right)$ and the value of adsorption intensity parameter $\mathrm{n}$ (dimensionless) which indicates the favorability of the adsorption (Mckay et al. 1982).

Temkin (Temkin and Pyzhev 1940) model is given by Eq.16 (Table 1); $A_{t}\left(L \cdot \mathrm{mg}^{-1}\right.$ ) is the equilibrium constant representing the maximum binding energy and $\mathrm{B}_{t}$ is a coefficient related to the adsorption heat. The R-P model (Redlich and Peterson 1959) combines both Freundlich and Langmuir models and it is an empirical equation that includes three parameters (Eq.17 Table 1), it can be used in a range of concentrations to explain the equilibrium of adsorption in homogeneous or heterogeneous systems. Eq.17 describes this isotherm where, $\mathrm{K}_{\mathrm{RP}}\left(\mathrm{L} . \mathrm{g}^{-1}\right)$ and $\alpha_{\mathrm{RP}}\left(\mathrm{L}_{\mathrm{mg}} \mathrm{mg}^{-1}\right)$ are the constants of the R-P isotherm and $\beta_{R P}$ is an exponent with values ranging between 0 and 1 ; the results of this model are shown in Table 3.

D-R model assumes two possible mechanisms (physical or chemical); Eq.18 in Table 1 represents this model, where $\epsilon\left(\mathrm{kJ}^{\mathrm{mol}}{ }^{-1}\right)$ is Polanyi's potential, that is calculated using Eq.19 where $\mathrm{R}$ represent the gas constant $\left(8.314 \times 10^{-3} \mathrm{KJ}^{\mathrm{K}} \mathrm{K}^{-1} \cdot \mathrm{mol}^{-1}\right)$ and $\mathrm{T}$ the temperature $(\mathrm{K})$. From the value of $\mathrm{B}_{\mathrm{DR}}$ (determined by regression Eq.18) it is possible to calculate the average free adsorption energy $\left(\mathrm{E}, \mathrm{kJ} . \mathrm{mol}^{-1}\right.$ ) using Eq.20, where $\mathrm{E}$ defines the mechanism of adsorption: chemisorption ( $\mathrm{E}$ is $>8$ $\left.\mathrm{kJ} . \mathrm{mol}^{-1}\right)$ or physisorption $\left(\mathrm{E}<8 \mathrm{~kJ} \mathrm{~mol}^{-1}\right.$ ) (Dubinin and Radushkevich 1947); values of $\mathrm{E}$ (Table 3) indicate that the process is governed by physisorption.

According to the statistical parameters $\left(\mathrm{R}^{2}\right.$, MAPE and $\left.\chi^{2}\right)$ shown in Table 3, Langmuir was the model that best fitted the experimental data; Fig.5 c-d shows predicted values in a dashed line.

\subsection{Thermodynamic parameters}

To determine the thermodynamic parameters, $K_{p}$ values were calculated from intercepts obtained from $\operatorname{Ln}\left(\mathrm{C}_{s} / \mathrm{C}_{e}\right)$ vs $\mathrm{C}_{\mathrm{s}}$ plots for each of the temperatures tested (as explained in the section 2.5); the results of the linear regressions are presented in the Fig.6 a-b.

According to Eq.21 (Table 1), $\Delta \mathrm{H}$ and $\Delta S$ were determined by plotting $\mathrm{Ln}\left(\mathrm{K}_{\mathrm{P}}\right)$ as a function of $\mathrm{T}$ ${ }^{1}$ (Fig.5-C-d), and the results are shown in Table 4 for $\mathrm{pH} 2$ and 4 ; these were considered satisfactory because the $R^{2}$ of the linear regressions were near 1 (at $p H=2, R^{2}=0.99$ and at $\left.p H=4, R^{2}=0.96\right) . \Delta G$ was calculated using Eq.25; $\Delta G$ values $(<0)$ indicate that RR195 adsorptions is a spontaneous and favorable process and the degree of spontaneity of the reaction decreased with increasing temperature (Zheng et al. 2015). 
$\Delta \mathrm{H}$ Values $(<0)$ implies that the adsorption phenomenon is exothermic. In this case, the absorbed energy generated from the rupture of the bond between the water molecules and the sorbent in the process of desorption of the solvent (water) is less than the total energy released in the formation of the bond between the sorbent and the dye molecules resulting in the release of extra energy in the form of heat (Saha and Chowdhury 2011).

Adsorption $\Delta \mathrm{H}$ values in the range from 80 to $200 \mathrm{~kJ}^{\mathrm{mol}}{ }^{-1}$ characterize chemical adsorption process (Saha and Chowdhury 2011); according to the results obtained (Table 5) and the nature of colorant-sorbent interactions mentioned in section 3.3, it is possible to conclude that the adsorption process is of physical/chemical nature.

The results for $\Delta S(<0)$ indicate that the process is governed by enthalpy, this implies a decrease in the disorder at the solid/liquid interface during the adsorption process which causes the adsorbed dye molecules to escape from the solid to the liquid phase (Saha and Chowdhury 2011).

Similar results of spontaneous and favorable process $(\Delta \mathrm{G}<0)$, exothermic $(\Delta \mathrm{H}<0)$ and $\Delta \mathrm{S}<0$ were reported for the adsorption of Reactive Red 189 onto epichlorohydrin-crosslinked chitosan beads (Chiou and Li 2003) and adsorption of methyl orange azo dye using unmodified Ch/alumina (Zhang et al. 2012).

\subsection{Regeneration and desorption of the biocomposite and effect of competitive ions}

Fig.7 shows the results of three adsorption cycles $\left(\mathrm{C}_{0}=200 \mathrm{mg} \cdot \mathrm{L}^{-1} ; \mathrm{pH}=2\right)$ and two desorption cycles ( $\mathrm{pH}=12)$ of RR195 using BChA. In the desorption stage it was evident that the BChA was capable of being regenerated and used in consecutive cycles of adsorption. The desorption of BChA was achieved by exposure to alkaline medium which deprotonated the amino groups of the biocomposite affecting the electrostatic interactions between the dye and the sorbent material (Crini and Badot 2008)

Using $\mathrm{BChA}$, the time required to complete the first and second desorption cycles was $3 \mathrm{~h}$ and $1.9 \mathrm{~h}$ respectively; these values were shorter than in the case of ChOxb, with desorption times of $15 \mathrm{~h}$ and $15.2 \mathrm{~h}$ for the first and second cycle respectively (Pérez-Calderón et al. 2020).

In the second and third adsorption cycles $Q_{e}$ values of $182.9 \mathrm{mg} \cdot \mathrm{g}^{-1}(\mathrm{SD}=0.04)$ and $122.5 \mathrm{mg} \cdot \mathrm{g}^{-1}$ $(S D=0.18)$ were reached respectively, indicating a reduction of $5.5 \%$ and $36.6 \%$ in the adsorption capacity of BChA with respect to the first cycle of adsorption; on the other hand the \%RE achieved after the third cycle of adsorption was $52.4 \%(S D=0.08)$. These results indicate that $B C h A$ is a material that can be regenerated and reused for the adsorption of RR195 while maintaining its structure and activity.

The effect of competitive ions at the tested concentration $\left(5 \mathrm{mmol} . \mathrm{L}^{-1}\right)$ showed that for $\mathrm{Cl}^{-}$and $\mathrm{NO}_{3}^{-}$the \%RE was $83.3(\mathrm{SD}=1.3)$ and $70.1 \%(\mathrm{SD}=1.0)$ respectively, indicating that the presence of these ions does not have a pronounced negative effect on the process. In the case of $\mathrm{NO}_{3}^{-}$, the \%RM 
539 ions and the protonated amino groups in the BChA affecting the dye removal process (Pérez540 Calderón et al. 2020).

\section{4. CONCLUSIONS}

542 Crosslinked oxalic acid-chitosan/alumina ceramic biocomposite (BChA) was synthesized as a novel 543 sorbent material for the removal of an anionic reactive azo dye (RR195) from wastewater. The 544 biocomposite was prepared using ceramic particles containing $75 \%$ alumina which were coated with 545 chitosan previously crosslinked with oxalic acid. The physico-chemical and structural characteristics 546 of BChA allowed to identify the presence of cross-linked chitosan in the biocomposite, interacting by 547 electrostatic bonds with alumina (III) oxalate compound, product of the functionalization of the 548 ceramic support.

549 Batch experiments showed that the maximum removal percentage $(>80 \%)$ occurs at $\mathrm{pH}=2$ due to 550 the crosslinking effect of the oxalic acid. This result shows that the coating of cross-linked oxalic acid-chitosan improved adsorption performance for RR195 compared to other chitosan-synthesized materials; this improvement is attributed to the increase of exposed free amino groups on the active surface of BChA. Another reason is the stable structure of the chitosan gained by the ionic cross-

554 linking with oxalic acid which avoids the solubilization of the biopolymer in acid medium.

555 Langmuir equation gave the best fit to the experimental sorption isotherm. The BChA showed a high 556 adsorption capacity ( $367 \mathrm{mg} \cdot \mathrm{g}^{-1}$ at $\mathrm{pH}=2,318 \mathrm{~K}$ ) which is the highest reported for RR195 removal in 557 comparison with other sorbents materials.

558 The governing adsorption mechanism was the electrostatic interaction between the anionic dye (due 559 to the sulfonate groups) and the free amino groups of the cross-linked chitosan, enabling the 560 successive desorption/regeneration cycles of the biocomposite. The kinetic behavior corresponded 561 to a pseudo second order model. Experiments performed at different temperatures allowed the 562 calculation of the thermodynamic parameters showing that the adsorption process was 563 spontaneous, exothermic and enthalpy controlled.

564 The presence of different tested anions affected the removal according to $\mathrm{NO}_{3}^{-}>\mathrm{Cl}^{-}$due to the 565 competing effect for the free amino sites.

566 The novel biocomposite showed a better stability at low $\mathrm{pH}$ and can be applied as a cost-effective 567 and environmentally friendly sorbent for azo anionic dye removal from wastewater. The use of the 568 oxalic acid cross-linked chitosan coating on a ceramic support improved the adsorption capacity 569 compared to other materials and allowed the use of the sorbent in acidic.

\section{5. ACKNOWLEDGMENTS}

571 The authors gratefully acknowledge the financial support from Universidad Nacional de La Plata 572 (UNLP). Consejo Nacional de Investigaciones Científicas y Técnicas (CONICET), Comisión de 573 Investigaciones Científicas (CIC) de la Provincia de Buenos Aires, ANPCYT and (Agencia Nacional 574 de Promoción Científica y Tecnológica) and Ministerio de la producción, Ciencia y Tecnologia and 
575 the collaboration of the Centro de Tecnología de Recursos Minerales y Cerámica (CETMIC) in the 576 characterization studies.

578 Not applicable

\section{CONSENT FOR PUBLICATION}

$580 \quad$ Not applicable

\section{AUTHOR CONTRIBUTIONS}

Peréz-Calderón, John: Conceptualization, Methodology, Investigation, Formal analysis, Writing-

Project administration, Funding acquisition.

\section{AVAILABILITY OF DATA}

588 The datasets used and/or analysed during the current study are available from the corresponding 589 author on reasonable request.

\section{COMPETING INTERESTS}

591 The authors of the manuscript title "Performance of Oxalic Acid-Chitosan/Alumina interest or non-financial interest in the subject matter or materials discussed in this manuscript.

\section{REFERENCES}

Alver E, Metin AU (2012) Anionic dye removal from aqueous solutions using modified zeolite: Adsorption kinetics and isotherm studies. Chem Eng J 200:59-67. https://doi.org/10.1016/j.cej.2012.06.038

Barik B, Nayak PS, Achary LSK, et al (2019) Synthesis of alumina-based cross-linked chitosanHPMC biocomposite film: An efficient and user-friendly adsorbent for multipurpose water purification. New J Chem 44:322-337. https://doi.org/10.1039/c9nj03945g

Boddu VM, Abburi K, Talbott JL, Smith ED (2003) Removal of hexavalent chromium from wastewater using a new composite chitosan biosorbent. Environ Sci Technol 37(19):4449-4456. https://doi.org/10.1021/es021013a 
Brugnerotto J, Lizardi J, Goycoolea FM, et al (2001) An infrared investigation in relation with chitin and chitosan characterization. Polymer (Guildf) 42:3569-3580. https://doi.org/10.1016/S00323861(00)00713-8

Chiou MS, Li HY (2003) Adsorption behavior of reactive dye in aqueous solution on chemical crosslinked chitosan beads. Chemosphere 50:1095-1105. https://doi.org/10.1016/S00456535(02)00636-7

Çiçek F, Özer D, Özer A, Özer A (2007) Low cost removal of reactive dyes using wheat bran. J Hazard Mater 146:408-416. https://doi.org/10.1016/j.jhazmat.2006.12.037

Crini G (2006) Non-conventional low-cost adsorbents for dye removal: A review. Bioresour Technol 97:1061-1085. https://doi.org/10.1016/J.BIORTECH.2005.05.001

Crini G (2015) Non-Conventional Adsorbents for Dye Removal. In: Sharma SK (ed) Green Chemistry for Dyes Removal from Waste Water: Research Trends and Applications. John Wiley \& Sons, Beverly,U.S.A, p 359

Crini G, Badot PM (2008) Application of chitosan, a natural aminopolysaccharide, for dye removal from aqueous solutions by adsorption processes using batch studies: A review of recent literature. Prog Polym Sci 33:399-447. https://doi.org/10.1016/j.progpolymsci.2007.11.001

Crini G, Torri G, Lichtfouse E, et al (2019) Cross-Linked Chitosan-Based Hydrogels for Dye Removal. In: Crini G, Lichtfouse E (eds) Sustainable Agriculture Reviews 36. Springer, Cham, pp $381-425$

Darjito D, Purwonugroho D, Ningsih R (2014) The Adsorption of Cr (VI) Using Chitosan-Alumina Adsorbent. J Pure Appl Chem Res 3:53-61

Dobson KD, McQuillan AJ (1999) In situ infrared spectroscopic analysis of the adsorption of aliphatic carboxylic acids to $\mathrm{TiO}_{2}, \mathrm{ZrO}_{2}, \mathrm{Al}_{2} \mathrm{O}_{3}$, and $\mathrm{Ta}_{2} \mathrm{O}_{5}$ from aqueous solutions. Spectrochim Acta Part $\mathrm{A}$ Mol Biomol Spectrosc 55:1395-1405. https://doi.org/10.1016/S1386-1425(98)00303-5

Dubinin M, Radushkevich L. (1947) The equation of the characteristic curve of activated charcoal. Proc Acad Sci Phys Chem Sect 55:327-329. https://doi.org/10.4236/ojs.2014.41001

Fadzallah IA, Majid SR, Careem MA, Arof AK (2014) A study on ionic interactions in chitosan-oxalic acid polymer electrolyte membranes. J Memb Sci 463:65-72. https://doi.org/10.1016/j.memsci.2014.03.044

Feret FR, Roy D, Boulanger C (2000) Determination of alpha and beta alumina in ceramic alumina by X-ray diffraction. Spectrochim acta, Part B At Spectrosc 55:1051-1061. https://doi.org/10.1016/S0584-8547(00)00225-1

Freundlich HMF (1906) Over the adsorption in solution. J Phys Chem 57:387-471. https://doi.org/10.1016/j.jclepro.2017.04.078

Ghosh A, Ali MA (2012) Studies on physicochemical characteristics of chitosan derivatives with dicarboxylic acids. J Mater Sci 47:1196-1204. https://doi.org/10.1007/s10853-011-5885-x

Gonçalves JO, Esquerdo VM, Roberto T, et al (2019) Chitosan-Based Hydrogels. In: Crini G, Lichtfouse E (eds) Sustainable Agriculture Reviews 36. Springer, Cham, pp 147-173

Haerifar M, Azizian S (2013) Mixed surface reaction and diffusion-controlled kinetic model for adsorption at the solid/solution interface. J Phys Chem C 117:8310-8317. https://doi.org/10.1021/jp401571m

Hassaan MA, Nemr AEI (2017) Health and Environmental Impacts of Dyes: Mini Review. Am J Environ Sci Eng 1:64-67. https://doi.org/10.11648/j.ajese.20170103.11

Jagtap S, Yenkie MKN, Labhsetwar N, Rayalu S (2011) Defluoridation of drinking water using 
chitosan based mesoporous alumina

Microporous

Mesoporous

Mater. https://doi.org/10.1016/j.micromeso.2010.12.028

Jóźwiak T, Filipkowska U, Szymczyk P, et al (2017) Effect of ionic and covalent crosslinking agents on properties of chitosan beads and sorption effectiveness of Reactive Black 5 dye. React Funct Polym 114:58-74. https://doi.org/10.1016/j.reactfunctpolym.2017.03.007

657 Leung H-W (2001) Ecotoxicology of glutaraldehyde: review of environmental fate and effects studies. Ecotoxicol Environ Saf 49:26-39. https://doi.org/10.1006/eesa.2000.2031

Li W-Y, Liu J, Chen H, et al (2013) Application of oxalic acid cross-linking activated alumina/chitosan biocomposites in defluoridation from aqueous solution. Investigation of adsorption mechanism. Chem Eng J 225:865-872. https://doi.org/10.1016/J.CEJ.2013.03.105

Liu X, Zhang L (2015) Removal of phosphate anions using the modified chitosan beads: Adsorption kinetic, isotherm and mechanism studies. Powder Technol 277:112-119. https://doi.org/10.1016/j.powtec.2015.02.055

Manzoor J, Sharma M (2020) Impact of Textile Dyes on Human Health and Environment. In: Wani KA, Jangid NK, Bhat AR (eds) Impact of Textile Dyes on Public Health and the Environment. IGI 667 Global, Hershey,PA,USA, pp 162-170

Mckay G, Blair HS, Gardner JR (1982) Adsorption of dyes on chitin. I. Equilibrium studies. J Appl Polym Sci 27:3043-3057. https://doi.org/10.1002/app.1982.070270827

Mi F-L, Wu S-J, Lin F-M (2015) Adsorption of copper(II) ions by a chitosan-oxalate complex biosorbent. Int J Biol Macromol 72:136-144. https://doi.org/10.1016/J.IJBIOMAC.2014.08.006

Pérez-Calderón J, Santos M V, Zaritzky N (2020) Synthesis, characterization and application of cross-linked chitosan/oxalic acid hydrogels to improve azo dye (Reactive Red 195) adsorption. React Funct Polym 104699. https://doi.org/https://doi.org/10.1016/j.reactfunctpolym.2020.104699

Pérez-Calderón J, Santos M V, Zaritzky N (2018) Reactive Red 195 dye removal using chitosan coacervated particles as bio-sorbent: Analysis of kinetics, equilibrium and adsorption mechanisms. J Environ Chem Eng 6:6749-6760. https://doi.org/10.1016/j.jece.2018.10.039

Redlich O, Peterson DL (1959) A useful adsorption isotherm. J Phys Chem 63:1024. https://doi.org/10.1021/j150576a611

Rekik SB, Gassara S, Bouaziz J, et al (2017) Development and characterization of porous membranes based on kaolin/chitosan https://doi.org/10.1016/j.clay.2017.03.008

composite. Appl Clay Sci 143:1-9.

Saha P, Chowdhury S (2011) Insight Into Adsorption Thermodynamics. In: Tadashi M (ed)

Temkin MJ, Pyzhev V (1940) Kinetics of ammonia synthesis on promoted iron catalysts. Acta Physicochim URSS 12:217-222

Tran HN, You S-J, Hosseini-Bandegharaei A, Chao H-P (2017) Mistakes and inconsistencies regarding adsorption of contaminants from aqueous solutions: a critical review. Water Res 120:88116. https://doi.org/10.1016/j.watres.2017.04.014

Vakili M, Rafatullah M, Salamatinia B, et al (2014) Application of chitosan and its derivatives as adsorbents for dye removal from water and wastewater: A review. Carbohydr Polym 113:115-130. https://doi.org/10.1016/j.carbpol.2014.07.007

Vijayaraghavan K, Padmesh TVN, Palanivelu K, Velan M (2006) Biosorption of nickel(II) ions onto Sargassum wightii: application of two-parameter and three-parameter isotherm models. J Hazard Mater 133:304-308. https://doi.org/10.1016/j.jhazmat.2005.10.016 
696 Wang W, Tian G, Wang D, et al (2016) All-into-one strategy to synthesize mesoporous hybrid silicate 697 microspheres from naturally rich red palygorskite clay as high-efficient adsorbents. Nuture:Scientific 698 Reports 6: 39599. https://doi.org/10.1038/srep39599

699 Weber WJ, Morris JC (1963) Kinetics of adsorption on carbon from solution. J Sanit Eng Div 89:3170060

701 Yagub MT, Sen TK, Afroze S, Ang HM (2014) Dye and its removal from aqueous solution by 702 adsorption: a review. Adv Colloid Interface Sci 209:172-184. 703 https://doi.org/10.1016/j.cis.2014.04.002

704 Zaharia C, Suteu D (2012) Textile Organic Dyes - Characteristics, Polluting Effects and 705 Separation/Elimination Procedures from Industrial Effluents - A Critical Overview. In: Puzyn T, 706 Mostrag A (eds) Organic Pollutants Ten Years After the Stockholm Convention - Environmental and 707 Analytical Update. InTech, London, pp 55-86

708 Zhang J, Zhou Q, Ou L (2012) Kinetic, isotherm, and thermodynamic studies of the adsorption of 709 methyl orange from aqueous solution by chitosan/alumina composite. J Chem Eng Data 57:412710 419. https://doi.org/10.1021/je2009945

711 Zhang L, Cheng Z, Guo X, et al (2014) Process optimization, kinetics and equilibrium of orange G 712 and acid orange 7 adsorptions onto chitosan/surfactant. J Mol Liq 197:353-367. 713 https://doi.org/10.1016/J.MOLLIQ.2014.06.007

714 Zheng L, Wang C, Shu Y, et al (2015) Utilization of diatomite/chitosan-Fe (III) composite for the 715 716 removal of anionic azo dyes from wastewater: Equilibrium, kinetics and thermodynamics. Colloids Surfaces A Physicochem Eng Asp 468:129-139. https://doi.org/10.1016/j.colsurfa.2014.12.015 
718 Figure 1. Structural characterization for alumina ceramic particles (CerPa), cross-linked oxalic acid719 chitosan/alumina ceramic biocomposite (BChA), Chitosan (Ch) and Oxalic Acid (OA): SEM surface morphology and EDS microanalysis spectrum of: a) CerPa. b) BChA. FTIR-ART transmission spectra: c) Ch, OA. d) CerPa, BChA. e) X-ray diffraction spectra of CerPa, BChA. f) TGA analysis of $\mathrm{Ch}, \mathrm{OA}$ and BChA.

Figure 2. Schematic diagram of the: a) Complexation of alumina from the ceramic particle by oxalic acid reaction. b) Electrostatic interaction between the free amino group of chitosan and the alumina (III) oxalate complex. c) oxalic acid cross-linking the chitosan molecule by means of ionic interactions

Figure 3. a) Effects of time and BChA doses on adsorption capacity (Q) b) Equilibrium removal $\left(R E_{e} \%\right)$ and equilibrium capacity $\left(Q_{e}\right)$ as functions of $B C h A$ doses $\mathbf{c}$ ) Effect of $p H$ on $\% R E_{e}$ and $Z$ potential before and after adsorption. Different letters in the $\% R E_{e}$ and $Q_{e}$ indicate significant differences between the samples $(P \leq 0.05)$.

Figure 4. a) Stereomicroscope and SEM micrographs of crosslinked oxalic acid-chitosan/alumina ceramic biocomposite (BChA) after adsorption of Reactive Red 195 (RR195).

b) Microanalysis spectrum EDS of the surface BChA after adsorption of RR195. c) Micrograph of the cross-section after the adsorption process. d) FTIR-ART transmission spectra of BChA after adsorption of dye (BChA+RR195).

Figure 5. Adsorption kinetics of Reactive Red 195 onto crosslinked oxalic acid-chitosan/alumina ceramic biocomposite (BChA) at different initial concentrations.

a) $100 \mathrm{mg} \cdot \mathrm{L}^{-1}$ b) $200 \mathrm{mg} \cdot \mathrm{L}^{-1}$. Adsorption isotherms of Reactive Red 195 using $\mathrm{BChA}$ at different $\mathrm{pH}: \mathrm{c}) \mathrm{pH}=2, \mathbf{d}) \mathrm{pH}=4$. Symbols represent experimental values and dash lines correspond to the fitting of the non-linear regression using: a-b) Pseudo second order (Ps.2 Order) model and c-d) Langmuir model.

Figure 6. Plot of $\mathrm{Ln}(\mathrm{Cs} / \mathrm{Ce})$ vs. Cs to obtain the partition constant in equilibrium $\left(\mathrm{K}_{\mathrm{P}}\right)$ for thermodynamic parameters determination at different $\mathrm{pHs}$ : a) $\mathrm{pH}=2$, b) $\mathrm{pH}=4$, The lines represent linear rgressions at each temperature. The table inserted in the graph shows the $\mathrm{K}_{\mathrm{P}}$ values obtained; the standard deviation of the values are given between brackets. Plot of $L n\left(K_{P}\right) v_{s} T^{-1}$ at different $\mathrm{pH}: \mathbf{c}) \mathrm{pH}=2, \mathbf{d}) \mathrm{pH}=4$.

Figure 7. Adsorption/desorption cycles of Reactive Red 195 (RR195) using crosslinked oxalic acidchitosan/alumina ceramic biocomposite (BChA). 


\section{Figures}

a)

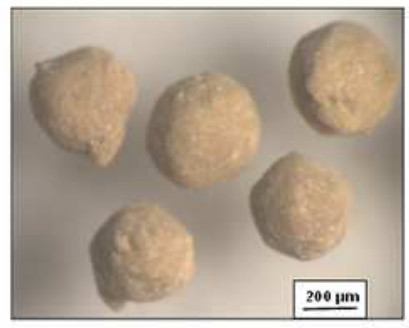

b)

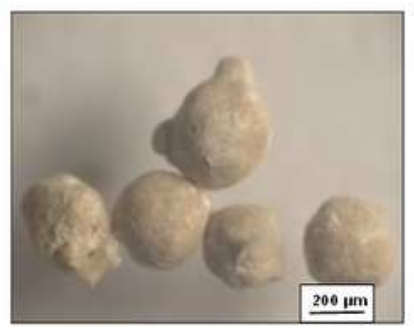

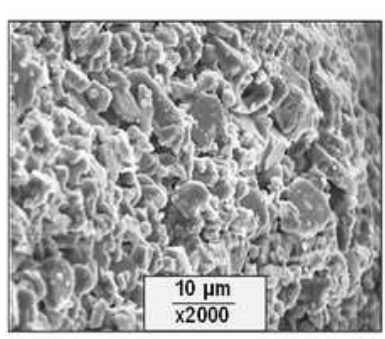
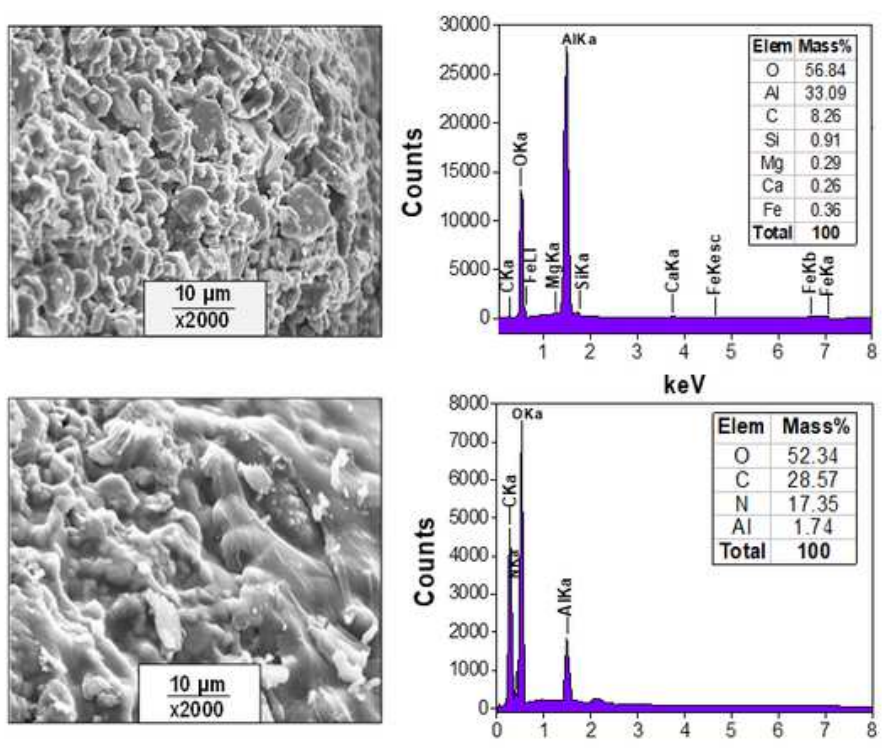

keV c)

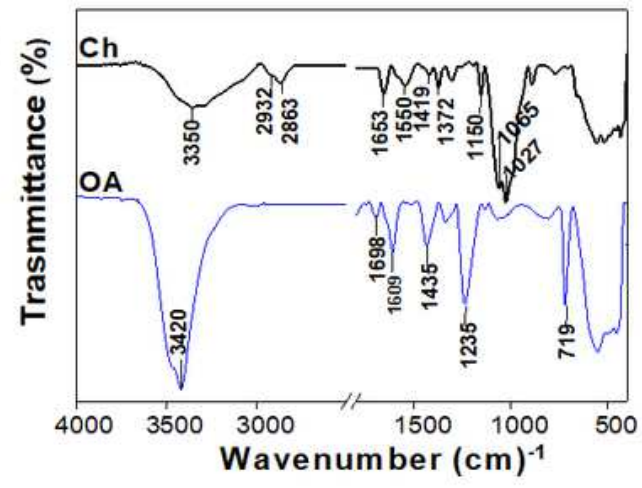

e)

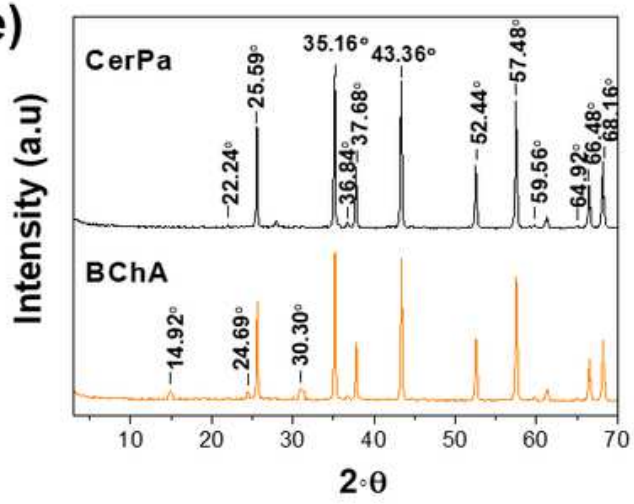

d)

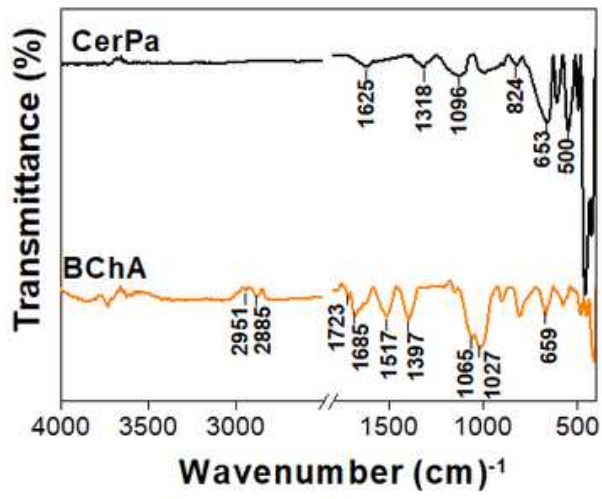

f)

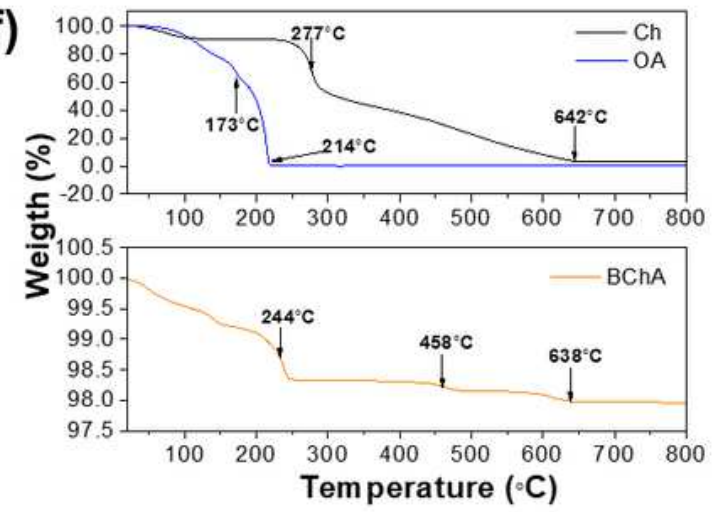

Figure 1

Structural characterization for alumina ceramic particles (CerPa), cross-linked oxalic acidchitosan/alumina ceramic biocomposite (BChA), Chitosan (Ch) and Oxalic Acid (OA): SEM surface 
morphology and EDS microanalysis spectrum of: a) CerPa. b) BChA. FTIR-ART transmission spectra: c) Ch, OA. d) CerPa, BChA. e) X-ray diffraction spectra of CerPa, BChA. f) TGA analysis of Ch, OA and BChA.

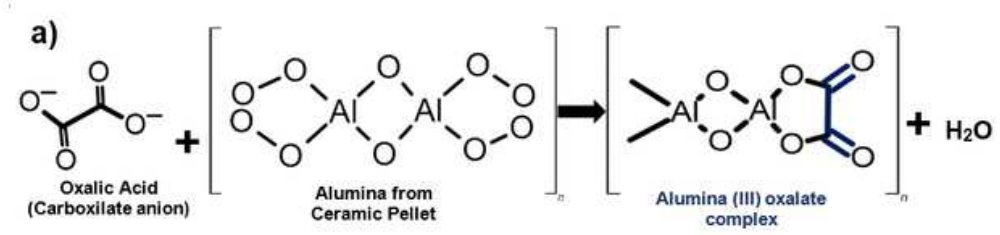

c)
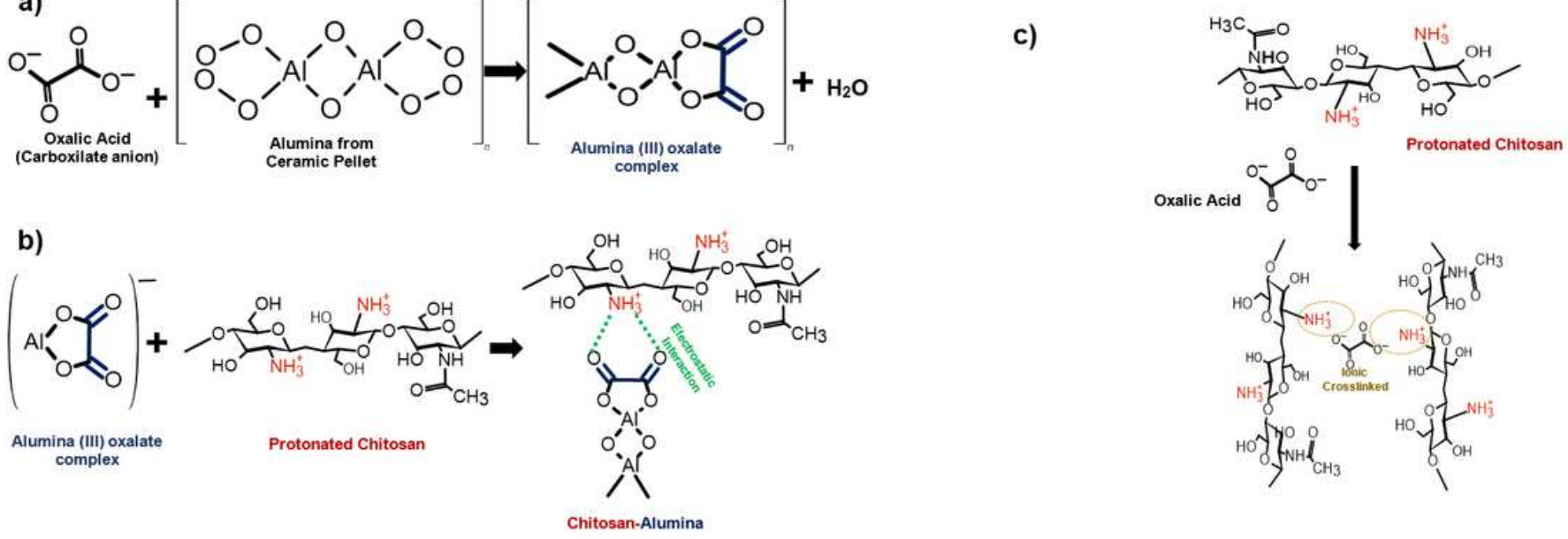

Figure 2

Schematic diagram of the: a) Complexation of alumina from the ceramic particle by oxalic acid reaction. b) Electrostatic interaction between the free amino group of chitosan and the alumina (III) oxalate complex. c) oxalic acid cross-linking the chitosan molecule by means of ionic interactions 
a)

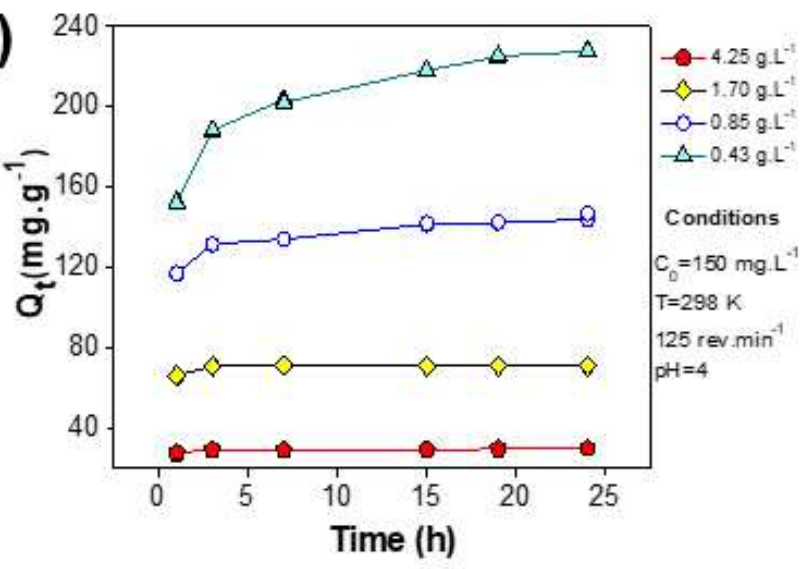

b)

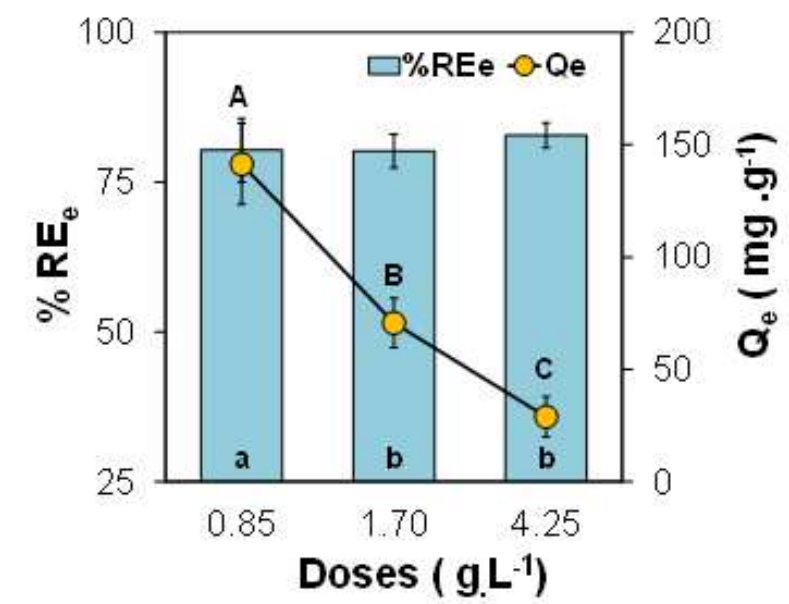

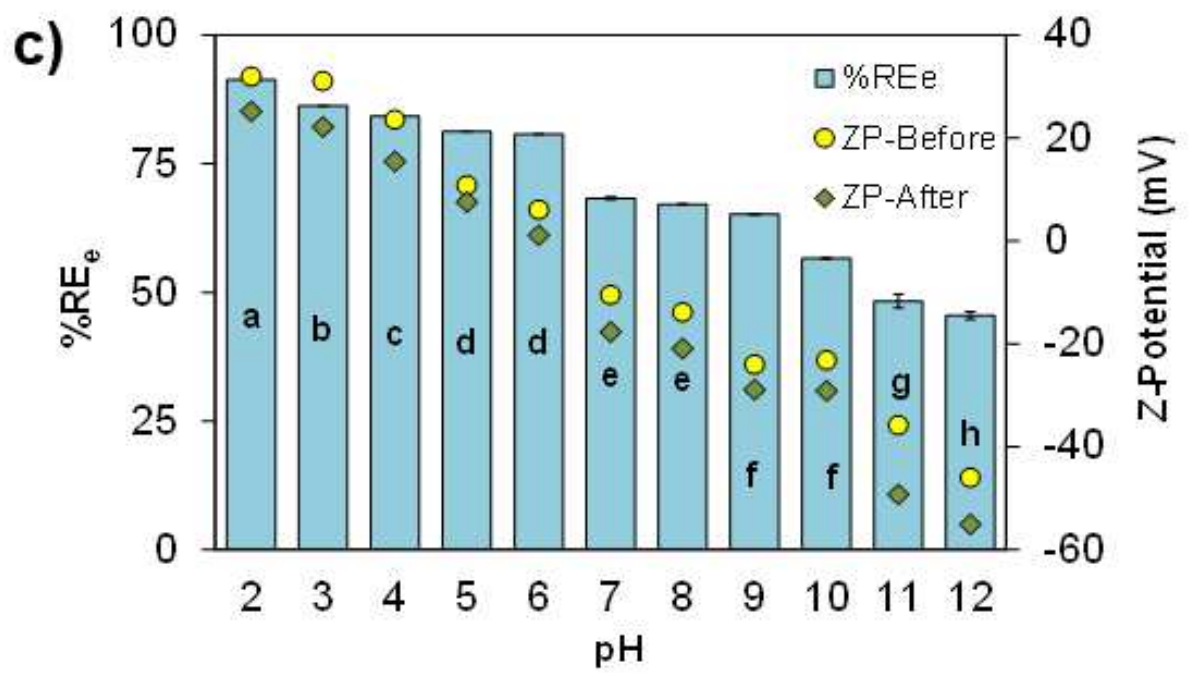

Figure 3

a) Effects of time and BChA doses on adsorption capacity (Q) b) Equilibrium removal (REe\%) and equilibrium capacity (Qe) as functions of BChA doses $\mathrm{c}$ ) Effect of $\mathrm{pH}$ on \%REe and $\mathrm{Z}$ potential before and after adsorption. Different letters in the \%REe and Qe indicate significant differences between the samples $(P \leq 0.05)$. 

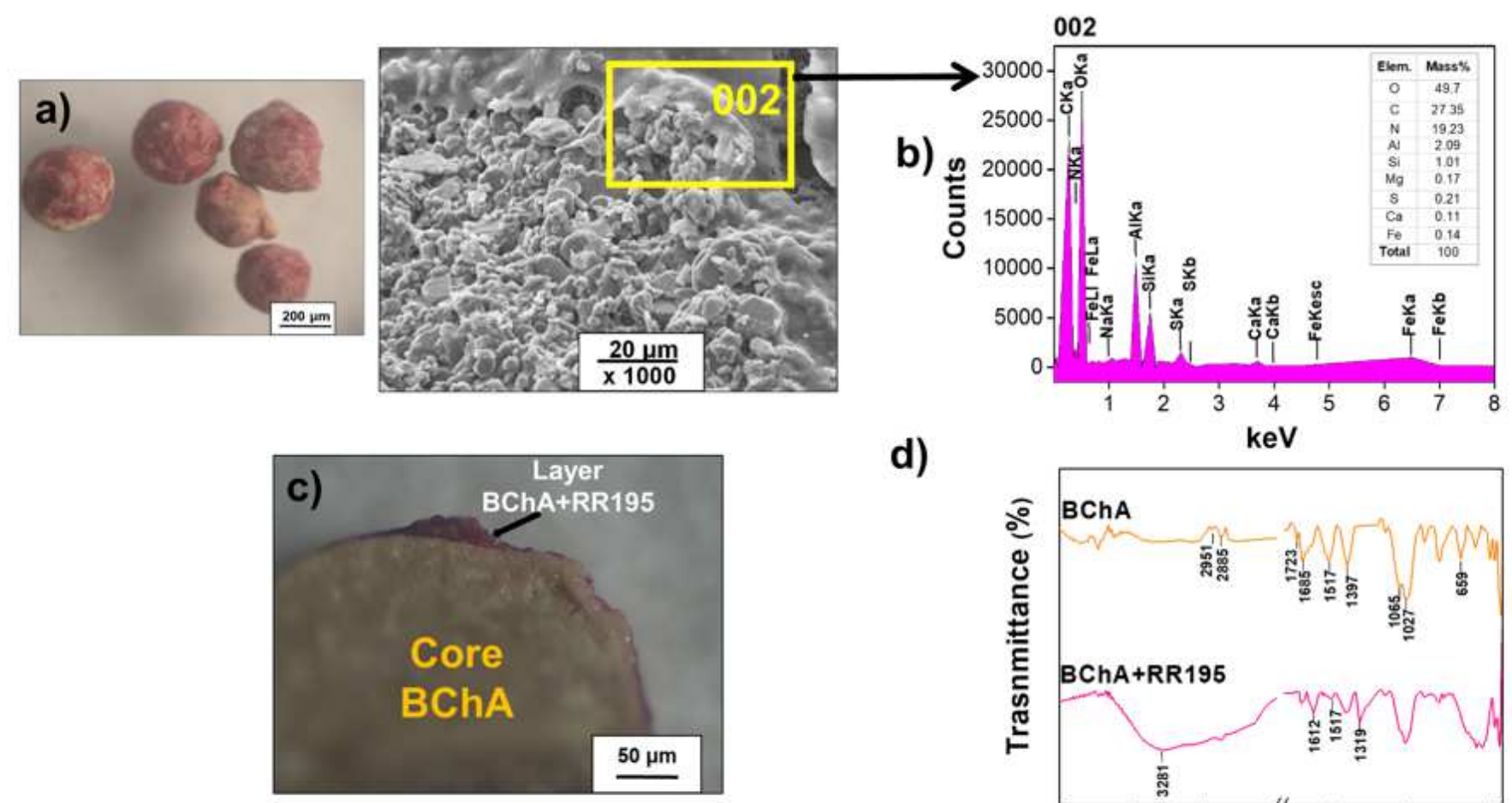

d)

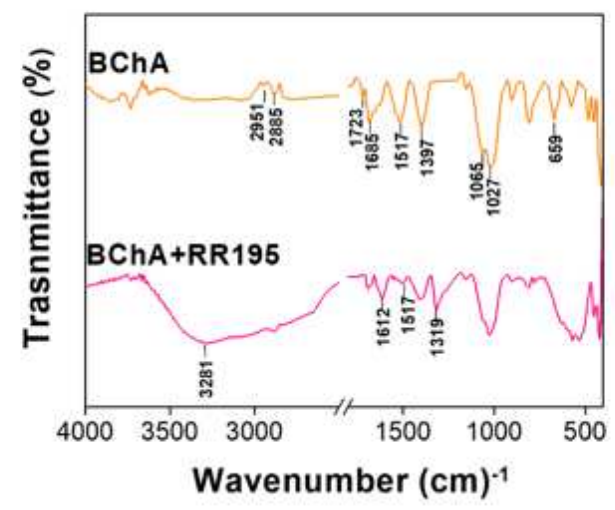

\section{Figure 4}

a) Stereomicroscope and SEM micrographs of crosslinked oxalic acid-chitosan/alumina ceramic biocomposite (BChA) after adsorption of Reactive Red 195 (RR195). b) Microanalysis spectrum EDS of the surface BChA after adsorption of RR195. c) Micrograph of the cross-section after the adsorption process. d) FTIR-ART transmission spectra of BChA after adsorption of dye (BChA+RR195). 

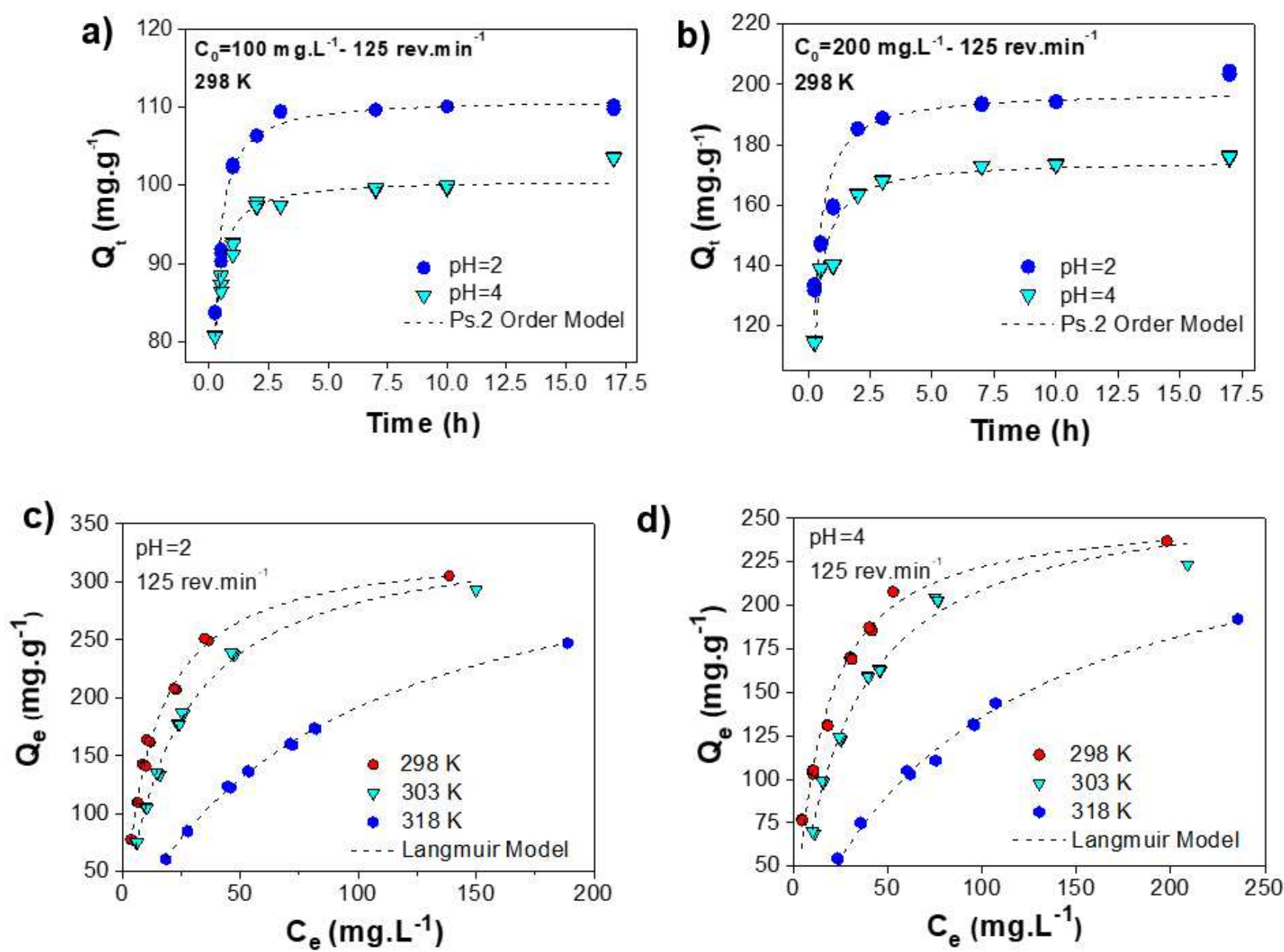

Figure 5

Adsorption kinetics of Reactive Red 195 onto crosslinked oxalic acid-chitosan/alumina ceramic biocomposite (BChA) at different initial concentrations. a) 100 mg.L-1 b) 200 mg.L-1. Adsorption isotherms of Reactive Red 195 using BChA at different $\mathrm{pH}$ : c) pH=2, d) $\mathrm{pH}=4$. Symbols represent experimental values and dash lines correspond to the fitting of the non-linear regression using: $a-b)$ Pseudo second order (Ps.2 Order) model and c-d) Langmuir model. 

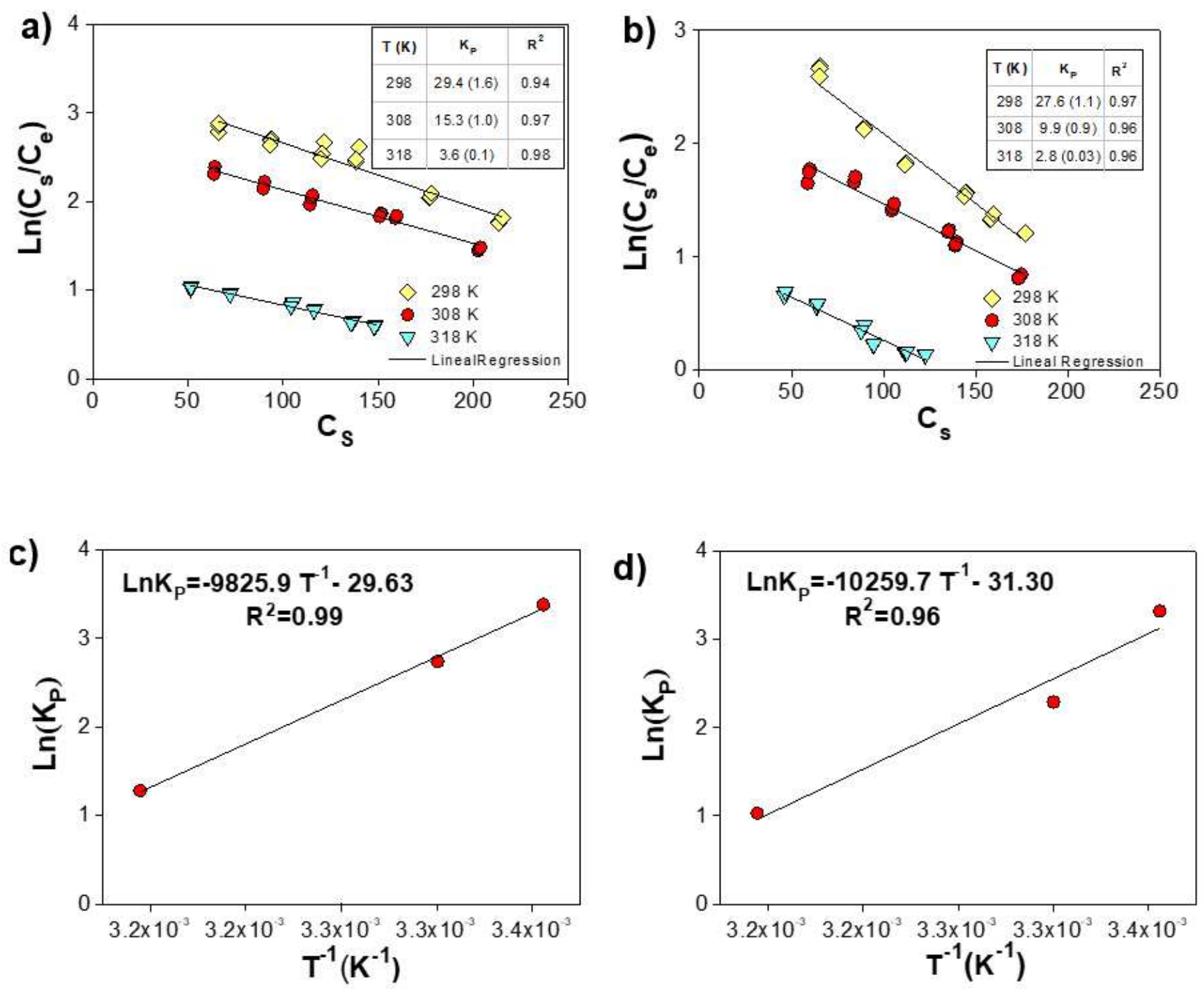

Figure 6

Plot of $\mathrm{Ln}(\mathrm{Cs} / \mathrm{Ce})$ vs. Cs to obtain the partition constant in equilibrium (KP) for thermodynamic parameters determination at different $\mathrm{pHs}$ : a) $\mathrm{pH}=2, \mathrm{~b}) \mathrm{pH}=4$, The lines represent linear rgressions at each temperature. The table inserted in the graph shows the KP values obtained; the standard deviation of the values are given between brackets. Plot of $\mathrm{Ln}(\mathrm{KP})$ vs $\mathrm{T}-1$ at different $\mathrm{pH}: \mathrm{c}) \mathrm{pH}=2, \mathrm{~d}) \mathrm{pH}=4$. 


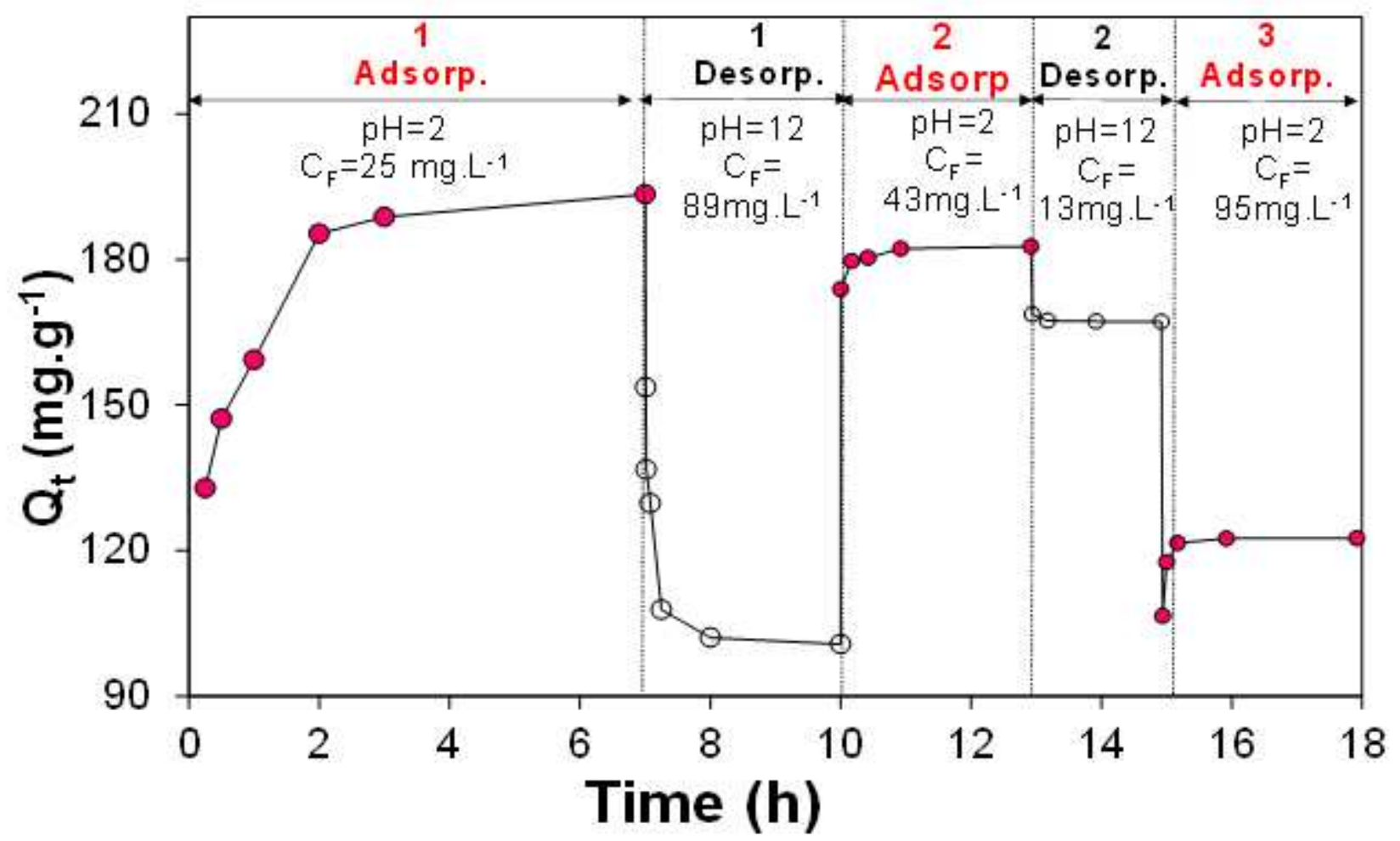

Figure 7

Adsorption/desorption cycles of Reactive Red 195 (RR195) using crosslinked oxalic acidchitosan/alumina ceramic biocomposite (BChA).

\section{Supplementary Files}

This is a list of supplementary files associated with this preprint. Click to download.

- Table1ESPR.docx

- Table2ESPR.docx

- Table3ESPR.docx

- Table4ESPR.docx

- Table5ESPR.docx

- SupplementaryInformation.docx 